\title{
UNIVERISTY OF OKLAHOMA
}

GRADUATE COLLEGE

DETECTING DECEPTION DURING A STRUCTURED INTERVIEW

\author{
A Dissertation \\ SUBMITTED TO THE GRADUATE FACULTY \\ in partial fulfillment of the requirements for the \\ degree of \\ Doctor of Philosophy
}

By

Lyle E. Leritz

Norman, Oklahoma

2004 
UMI Number: 3117197

\section{INFORMATION TO USERS}

The quality of this reproduction is dependent upon the quality of the copy submitted. Broken or indistinct print, colored or poor quality illustrations and photographs, print bleed-through, substandard margins, and improper alignment can adversely affect reproduction.

In the unlikely event that the author did not send a complete manuscript and there are missing pages, these will be noted. Also, if unauthorized copyright material had to be removed, a note will indicate the deletion.

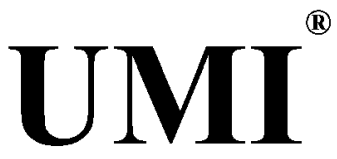

UMI Microform 3117197

Copyright 2004 by ProQuest Information and Learning Company.

All rights reserved. This microform edition is protected against unauthorized copying under Title 17, United States Code.

ProQuest Information and Learning Company 300 North Zeeb Road

P.O. Box 1346

Ann Arbor, Ml 48106-1346 
(C) Copyright by Lyle E. Leritz 2004

All Rights Reserved. 
DETECTING DECEPTION DURING A STRUCTURED INTERVIEW

A Dissertation APPROVED FOR THE DEPARTMENT OF PSYCHOLOGY

BY

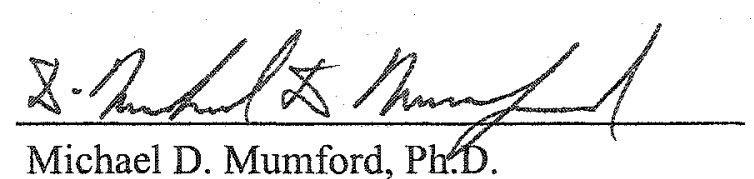

Michael D. Mumford, $\mathrm{Ph}$. .

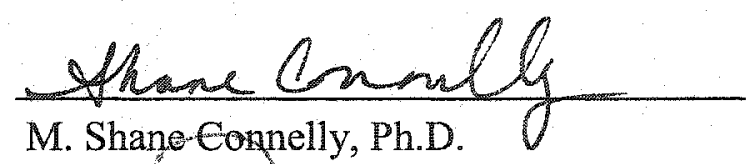

M. Shane Connolly, PhD.

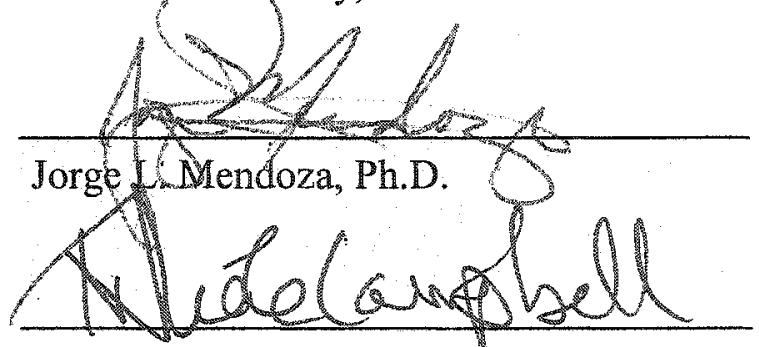

T. Nicole Campbell, PhD.

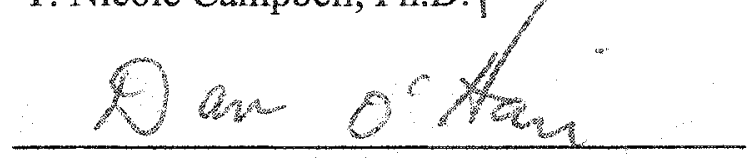

H. Dan O'Hair, Ph.D. 


\section{Acknowledgements}

I wish to express my sincere appreciation and gratitude to Michael Mumford for his guidance and supervision throughout my graduate training. As well, I would like to thank Shane Connelly for her advice and support over the years. I would also like to thank the dissertation committee members, Jorge Mendoza, Nicole Campbell, and Dan O'Hair for their valuable comments.

On a personal note, I would like to acknowledge the support, friendship, and patience of my wife Bernadette. Without her sacrifices I would not have completed graduate training.

Portions of this research were sponsored by the Department of Defense Polygraph Institute. The views presented here are those of the author and do not necessarily reflect the views of the DOD-PI. 
Table of Contents

Acknowledgements.................................................. iv

List of Tables........................................................ vi

List of Figures.......................................................... vii

Abstract............................................................. viii

Introduction..................................................................

Polygraph Testing............................................... 1

Verbal Analysis...................................................... 3

Alternative Approach............................................ 7

Training......................................................... 14

Method................................................................... 16

Covariate Materials................................................ 17

Training Materials........................................................ 20

Interview Veracity................................................. 24

Confederate Training............................................... 25

Criteria Checklist................................................. 26

Procedure................................................... 27

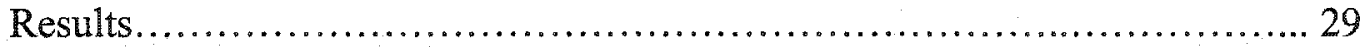

Covariates.......................................................... 31

Criteria Accuracy...................................................... 33

Overall Judgments............................................ 43

Discussion............................................................ 44

References.......................................................... 49

Appendices............................................................ 53 
List of Tables

Table

1 Descriptive Statistics and Reliability Coefficients for the Covariate Measures............................................................ 30

2. Covariate Effects.................................................. 32

3 Overall Training and Veracity Effects...................................... 34 


\section{List of Figures}

Figure

1 Truth process model.............................................. 8

2 Deception process model............................................. 9

3 Number of criteria correct during the interview........................ 38

4 Percent correct during the interview.................................... 39

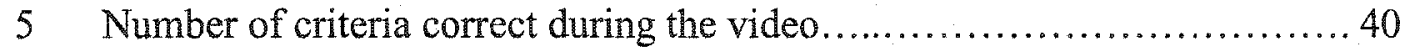

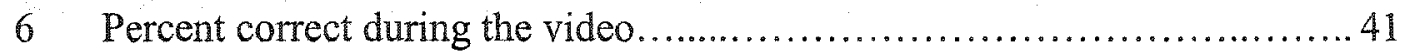




\begin{abstract}
Deception is a part of everyday life for many people. Given this reality, how can employers be certain employees are being relatively honest during interviews? Can an interviewer be trained to detect deception while conducting an interview? The purpose of this research was to determine if an interviewer could be trained to detect deception while conducting an interview. To address this, participants were given one of three levels of training, including structured interview training, deception detection training, and probe question training. Each level of training included the previous level(s) of training. Following training, participants interviewed another person using the criteria checklist from training. After the interview, participants completed a questionnaire where they rated, among other things, honesty and deceptiveness. Additionally, participants reviewed the interview on videotape, again using the criteria checklist and completing a second questionnaire. Results indicated that training improved performance relative to no training in terms of criteria application. However, training beyond the criteria (e.g., probe training) reduced the ability to use the criteria checklist, but did not reduce accuracy in applying the criteria. Additionally, training did not influence the overall judgments. Finally, there were no differences between the interview and the video review in terms of judgments and criteria application.
\end{abstract}




\section{Detecting Deception During a Structured Interview}

Deception is a part of everyday life for many people. The purpose and forms of deception vary widely, ranging from simple deception to prevent hurt feelings to calculated, intricate deception to cover up wrongdoing, indiscretions, or even crimes. DePaulo defines deception as "a deliberate attempt to mislead others" (DePaulo et al., 2003). Detecting deception is particularly important for criminal investigations, public and private organizations, as well as national security. Given this reality regarding deception, how can employers be certain prospective employees are being relatively honest during interviews? Can an interviewer be trained to detect deception while conducting an interview? The primary purpose of this research is to determine if different levels of training impact an interviewer's ability to detect deception while conducting a structured interview.

Traditionally, attempts at detecting deception in a particular situation, as opposed to the general disposition towards honesty commonly assessed through integrity tests (Sackett, Burris, \& Callahan, 1989), have been made via polygraph testing. Polygraph testing utilizes biological feedback to infer deceptiveness with the assumption that physiological reactions differ between honest and deceptive people.

\section{Polygraph Testing}

Polygraph testing utilizes changes in physiological responses such as blood pressure, respiration, pulse rate, and galvanic skin response to infer deceptiveness (Tacono \& Patrick, 1997). The vast majority of research with the polygraph has been conducted in criminal investigation contexts. While the polygraph has demonstrated evidence for greater than chance accuracy in deception detection, there are differences between 
employment and investigation situations that limit generalizing these results to employment settings (Sackett \& Decker, 1979). Additionally, the Employment Polygraph Protection Act of 1988 prevents private employers from using the polygraph as a part of the hiring process. Note, however, this act does not prevent government and law enforcement agencies from using the polygraph for employment purposes.

There are several techniques available when using the polygraph. The most common technique is referred to as the control question test. This method compares physiological responding to directly relevant questions with physiological responding to control questions. The rationale behind this approach is that truthful individuals will react more strongly to the control questions while deceptive individuals will react more strongly to the relevant questions. The validity of this procedure is questionable as it has not been vigorously tested and often yields false positives of $30 \%$ or greater (Saxe, Dougherty, \& Cross, 1985). An alternative technique, known as the guilty knowledge test, is intended to assess if an individual possesses knowledge that would be known only to those at the scene of a crime. While this approach results in fewer false positives and greater accuracy overall (Lykken, 1981), it is more appropriate for use in criminal contexts than employee selection.

In general, there is much controversy surrounding use of the polygraph in both criminal and employment contexts (Lykken, 1979; Raskin \& Podlesny, 1979). While physiological measurements obtained for polygraph testing are standardized the administration procedures vary widely with differences in questions asked, responses recorded, use of data, and examiner skill and preferences (Miner \& Capps, 1996). More importantly, there is no evidence that the polygraph is a valid predictor of past or future 
indiscretions (Lykken, 1981). In addition to these concerns, the polygraph is expensive to administer, requires extensive administrator training, and cannot legally be used by private employers for selection purposes. As a result, the private sector must rely on alternate methods for detecting truth and deception on the part of prospective employees. One technique that has gained in popularity is the use of verbal analysis.

\section{Verbal Analysis}

Verbal analysis involves the examination of the structure and themes in verbal statements (Vrij, Edward, Roberts, \& Bull, 2000). Analysis of verbal statements is typically accomplished via audio recordings or written transcripts. Much of the research on verbal analysis has been conducted in laboratory settings with little resemblance to employment settings. In general, several verbal analytic techniques represent general trends in this arena including Criteria-Based Content Analysis (Steller \& Köhnken, 1989), Reality Monitoring (Sporer, 1997), and Scientific Content Analysis (Sapir, 1987). Criteria-Based Content Analysis (CBCA) was originally developed for verifying the credibility of children's eyewitness testimonies in sexual abuse cases and has subsequently been applied to general statements with some success. The CBCA approach works under the assumption that the content, quality, and expression of an individual's verbal statements provide clues to the degree of truthfulness present in the statements (Undeutsch, 1967). There are 14 to 17 criteria available for use with the CBCA approach. The more criteria present in the statement the more likely the statement is true. Research conducted with CBCA has produced both support (Köhnken, Schimossek, Aschermann, \& Höfer, 1995; Landry \& Brigham, 1992) and mixed results (Ruby \& Brigham, 1997, 1998). 
Similar to CBCA, Reality Monitoring is oriented towards truth verification with more criteria indicative of truthful statements. Reality Monitoring differs from other verbal analysis techniques in that it is based on strong theory. This technique operates under the hypothesis that memories of actual experiences, versus those that are contrived, display different characteristics when relayed verbally (Johnson \& Raye, 1981). Research using this technique has been conducted in the eyewitness context with some success (Leippe, Manion, \& Romanczyk, 1992; Schooler, Gerhard, \& Loftus, 1986). However, other research has not supported the ability of these criteria to discriminate truthful and deceptive statements (Porter \& Yuille, 1996). Additionally, the use of Reality Monitoring to classify intentionally deceptive statements has only been examined in a few studies. While only a few studies have examined this approach, it remains one of the few approaches with strong underlying theory that has received empirical support.

In addition to the truth verification techniques such as CBCA and Reality Monitoring, there are other approaches that are useful for detecting deception. One such approach, Scientific Content Analysis (SCAN), was developed based on interrogation experience (Sapir, 1987). Similar to the CBCA and Reality Monitoring approaches, SCAN is based upon the notion that people speak differently when they are not being truthful. Deceptive statements are proposed to be lengthier, have a greater number of unnecessary connectors that provide no new facts or information, and include greater deviations in pronoun usage. SCAN differs from other techniques in that there is no explicit list of criteria. Rather, SCAN training materials include numerous examples of verbal patterns associated with deception under three main categories: pronouns, changes in language, and ambivalent sentences. Unfortunately, little empirical research has been 
conducted utilizing this approach. In one experimental study, the SCAN system was used in conjunction with three other content analysis techniques (Porter \& Yuille, 1996). Resulting analyses indicated that the SCAN system did not reliably discriminate truthful and deceptive statements. It should be noted, however, that this system was used in conjunction with other criteria and was not tested independently. It is possible that this system taps constructs similar to those in the other techniques. These findings are not surprising given the lack of specific criteria for the SCAN system.

These three verbal analysis systems are not the only systems available. Other existing systems include Weintraub's Verbal Behavior Cues (Weintraub, 1989), Investigative Discourse Analysis (Rabon, 1994), and Practical Kinesic Analysis (Walters, 1996). However, CBCA, Reality Monitoring, and SCAN represent typical approaches to verbal analysis. Although the CBCA and Reality Monitoring techniques are truth orientated, nearly all deception detection research has focused on deception cues rather than truth cues (DePaulo et al., 2003). Despite this focus on deception cues, most systems developed to detect deception result in a truth bias on the part of judges regardless of the veracity of the message (McCornack \& Parks, 1986). That is, individuals are more likely to attribute truth than deceit to the messages of others. There are additional trends worth noting. For example, women are superior to men when judging a liking or disliking of a communication in general. However, this difference is less evident when judging honesty and deceptiveness in verbal statements (Rosenthal \& DePaulo, 1979). A more important trend in deception research is that most studies demonstrate an overall accuracy rate just above $50 \%$. The average rate of successful classification is $57 \%(\mathrm{Kraut}, 1980)$ with most studies ranging between $45 \%$ and $70 \%$ (Kalbfleisch, 1994). Even individuals who have 
received deception training do not produce accuracy rates above $75 \%$ (deTurck \& Miller, 1990). However, researchers have pointed out that this accuracy rate is misleading (Levine, Park, \& McCornack, 1999). When examined separately, most errors occur with deceptive statements. That is, truthful statements are most often correctly identified while deceptive statements are often classified at less than chance rates.

To summarize, existing alternatives to polygraph testing exist in the form of verbal analysis techniques. Furthermore, these techniques have shown promise. However, there are several limitations to existing methods. With the exception of Reality Monitoring, many existing systems are not strongly rooted in theory, rather, they are based on hypotheses or experience. Lacking theoretical foundation does not imply that these systems do not work or are inferior. However, to create a legally defensible selection system it is essential to establish relationships between candidate attributes and job requirements, which is best done through theory and research (Guion, 1990). Other weaknesses in existing systems limit their use in employment settings. CBCA was originally developed for use in child abuse cases and has received little attention in the employment arena. Similarly, Reality Monitoring has been successfully applied in interrogation contexts but generalization to employment settings is questionable. The major weakness of the SCAN approach is a lack of concrete or specific criteria available for analyzing verbal statements. Additionally, this approach is based on the experience of an interrogator and lacks a theoretical model. Taking these limitation into account, it seems prudent to consider an alternative approach that is based on broad theory and developed specifically for employment contexts. 
Alternative Approach

To address the limitations of existing verbal analytic approaches Connelly and her colleagues (Connelly et al., 2003) developed a new verbal analysis system with theoretically-based criteria. To begin, literature reviews were conducted in six broad areas of research. These areas included autobiographical memory (Lancaster \& Barsalou, 1997; Schank \& Abelson, 1995), cognitive verbal processes (Clancy, 1999; Mumford, Schultz, \& Van Doorn, 2001), emotional expression (Bowers, 1981; Friedman \& Riggio, 1999), defense mechanisms (Freud, 1920/60; Wade \& Tavris, 1998), linguistics (McCornack, 1992; Semin \& Feidler, 1988), and self-presentation (Hilton, 1998; Stevens \& Kristof, 1995). Based upon this literature review the researchers developed two conceptual models reflecting processes associated with truth telling and lying. These models are presented in Figure 1 (Truth model) and Figure 2 (Deception Model).

As depicted in the models, both truthful and deceptive responses begin with the same basic processes until an initial decision is made on whether and to what extent the communicator will engage in deceit, at which point the models diverge. To begin, an individual is in a situation requiring a verbal response and situational demands are perceived. The degree to which the situation is personally relevant is influenced by basic beliefs and values as well as the degree of perceived threat or opportunity. This, in turn, leads to the development of goals to reduce threat or position opportunities. Goal development leads to an initial memory search for information relevant to meeting situational demands, and, along with basic beliefs and values, will guide the decision to lie or tell the truth. Once a decision has been made, goals, beliefs, and values will also influence the nature of the statements given. 
Figure 1

Truth Process Model

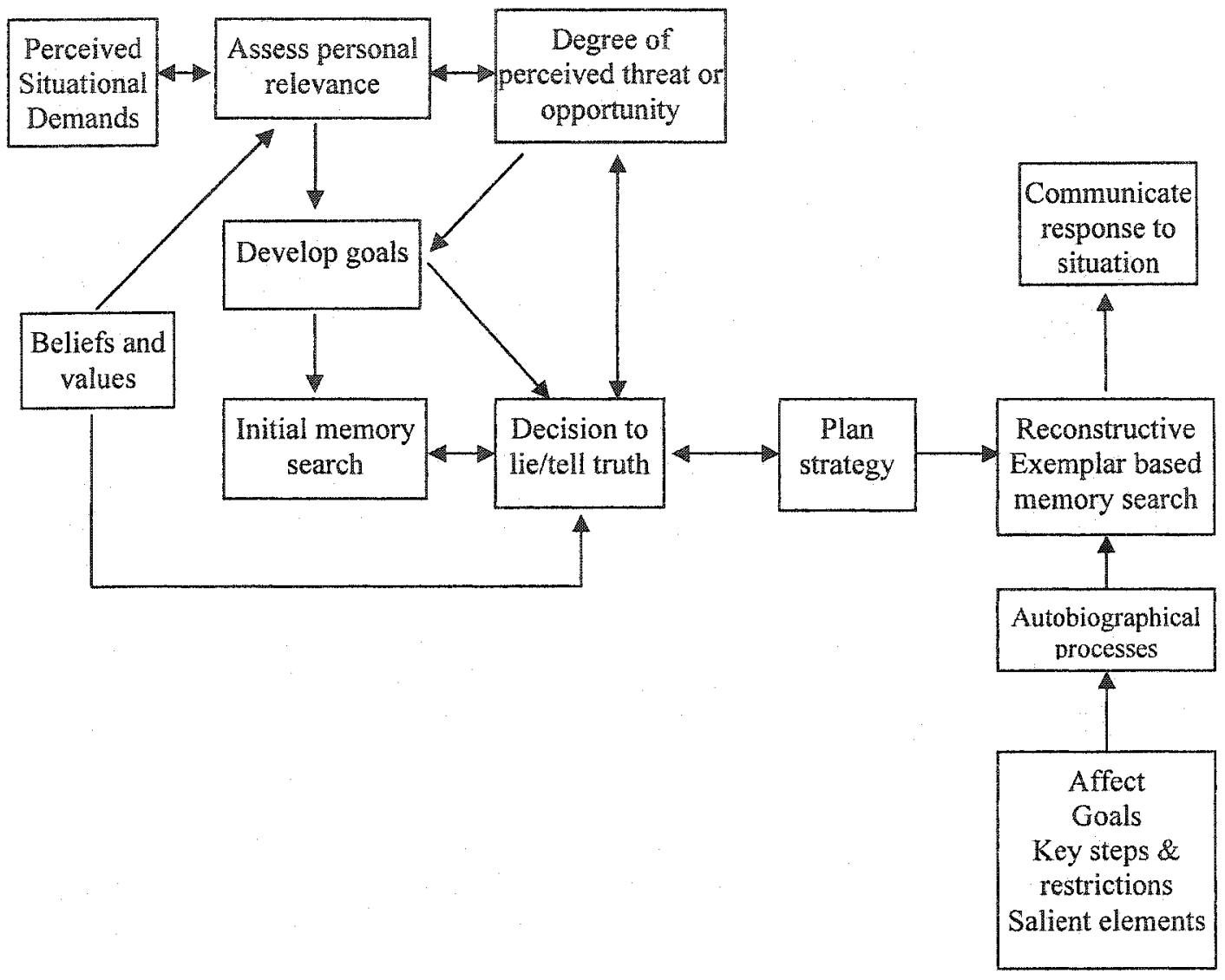


Figure 2

Decention nureses model

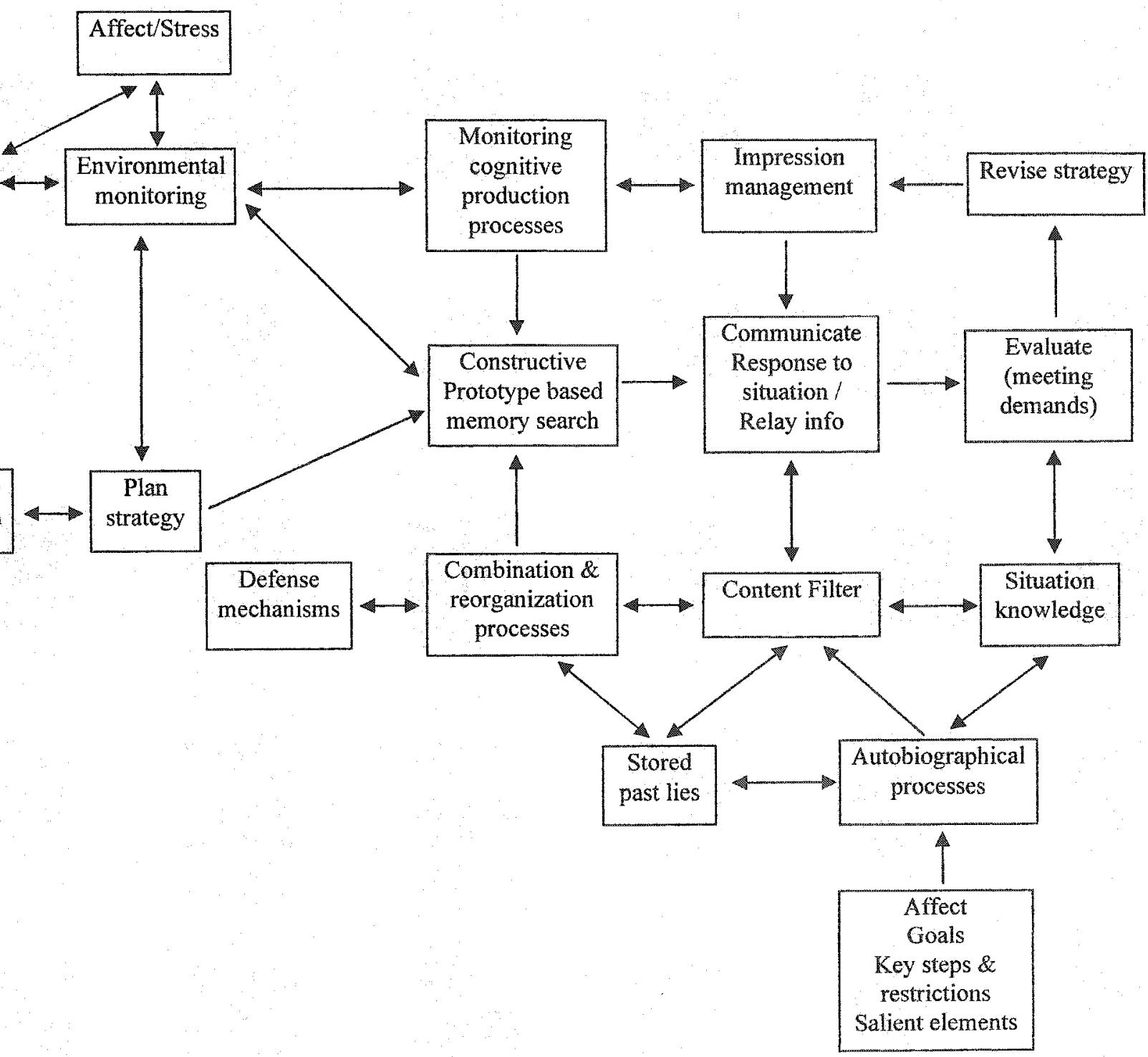


Once the decision about whether and how to deceive is made and the communicator is aware of this intention, planning processes are activated. Following this, there are many factors that influence the final lie including environmental monitoring, affect and stress, combination/reorganization processes, impression management, filtering, autobiographical processes, and accessing past lies.

When a decision to tell the truth is made, the process is less complex than that for lying. As before, the process begins with a situation requiring a verbal response and perceived situational demands. Personal relevance is influenced by beliefs and values as well as the degree of perceived threat or opportunity leading to the development of goals and an initial memory search. Similar to the deception process, planning processes are subsequently engaged. This leads to event reconstruction, which is influenced by autobiographical processes. One of the key differences between the two processes is that the truth process is reconstructive while the deception process is constructive. Other differences include, but not are not limited to, amount of affect or stress (related to the veracity of the message), combinatorial processes, and strategy revision.

As is evident in these models, the process of communicating truthful and deceptive statements is complex, albeit more so for deceptive statements. Thus, it should not be surprising that there is no universal indicator of deception. Consequently, these models imply that deception criteria should be drawn from a broad area of psychological and interpersonal research. Based on these models and the six general areas of research, the researchers developed criteria in an attempt to detect deception. Based on the implication of key points from literature in each area, hypotheses regarding the structure and content of people's verbal statements were generated. These hypotheses were then 
used to guide production of criteria that may indicate truth or deception in a verbal statement. Following this, the researchers reviewed the criteria coming to a group consensus regarding which ones to keep followed by additional refinement and modification. This process resulted in 196 criteria across the six areas.

To test the new criteria, two experimental studies were conducted. These two studies were designed to answer four general questions. First, are the criteria, as a set, able to discriminate truthful from fabricated statements? Second, does the level of interview structure impact the effectiveness of the criteria? Third, what is the impact of allowing respondents to prepare answers in advance? Finally, what is the impact of level of deception (e.g., distortion, concealment, and complete fabrication) on the effectiveness of the criteria?

To answer these questions, two similar protocols were developed. Both protocols required participants to participate in a structured interview under the assumption that they were interviewing for a real job. For the first protocol, participants were randomly assigned to one of three levels of interview structure: low, moderate, or high. Half of these participants were instructed to be completely honest while the other half were instructed to provide entirely fabricated responses. For the second protocol, all participants were interviewed using the high structure interview. However, for this experiment, participants were instructed to 1) be entirely truthful, 2) fabricate their answers, 3) use actual life experiences distorting negative information that would make them look less desirable, or 4) enhance positive information and conceal negative information to make them look more desirable. Additionally, half of the participants in 
each of these instruction conditions were given the interview questions ahead of time so they could prepare their responses.

The first study was designed to assess the question regarding level of interview structure. Discriminant function analyses indicated that criteria from the areas of selfpresentation, emotional processing, and defense mechanisms discriminated truthful from fabricated statements. However, when statements were obtained under low structured interview, no criteria sets discriminated truthful from fabricated responses. Classification rates using these criteria ranged from $70 \%$ to $90 \%$ with truthful statements correctly classified more often than fabricated statements. When these areas were combined into a single analysis, classification rates jumped to $89 \%$ and $96 \%$, respectively. In addition to these findings, it is important to note that, when examined individually, several criteria from each of the non-discriminating areas were as, or more, effective than criteria from the discriminating areas.

The second study was designed to assess allowing advanced preparation as well as type, or level, of deception. Discriminant function analyses indicated criteria from all six areas significantly discriminated the four groups. However, the effectiveness of each area was dependent upon deception type and whether or not the participant was allowed advanced preparation. In particular, criteria from autobiographical memory, selfpresentation, emotional processing, linguistics, and cognitive processes discriminated under the no preparation condition. Criteria from self-presentation and defense mechanisms discriminated under the preparation condition. Classification rates using these criteria ranged from $44 \%$ to $65 \%$. Note, these rates are lower than those from the previous study due to the increase in number of groups (from two to four). However, the 
patterns of function scores differed for each area across the three types of deception. When criteria across these three areas were used in one overall analysis, classification rates increased for all groups, ranging from $53 \%$ to $71 \%$.

In addition to testing the new verbal analysis criteria, the statements obtained were examined using criteria from $\mathrm{CBCA}$ and Investigative Discourse Analysis (IDA). Across the two studies, the new verbal analysis system outperformed both $\mathrm{CBCA}$ and IDA in terms of classification rates. While CBCA criteria were useful for predicting group membership in these studies none of the IDA criteria discriminated among the groups. These findings are not surprising given the limitations of these systems, in particular, that they were not developed for use in employment settings.

To summarize, criteria from the new verbal analysis system were useful for discriminating truthful from deceptive statements. Additionally, $\mathrm{CBCA}$ criteria discriminated these statements, though to a lesser degree, while IDA criteria were not successful at discriminating truthful and deceptive statements. Thus, experiments from these studies established the potential utility for this system. To analyze data for these studies, verbal statements were transcribed into typewritten text and trained raters coded each transcript for presence of each criterion. While this is useful, and necessary, for establishing the new verbal analysis system, it leaves several questions unaddressed. First, as a whole, there are 196 criteria comprising the system. Coding statements with this many criteria requires extensive amounts of time. One question that arises is, can a subset of these criteria be used to obtain similar rates of classification? A second, yet related, question is, can an interviewer use a subset of these criteria while conducting an interview to detect deception? To address these questions a subset of useful criteria must 
be identified. Second, interviewers need to be trained to use these criteria while conducting an interview.

\section{Training}

Training refers to the systematic acquisition of skills resulting in improved performance (Goldstein \& Ford, 2002). When training is effective, trainees will have learned the material and will behave differently from prior behavior as well as from those not receiving training (Haccoun \& Saks, 1998). Typically, training is evaluated on four levels, including trainee reaction, amount of learning, behavioral change, and organizational improvement (Kirkpatrick, 1987). Reaction is typically measured via posttraining questionnaires. However, there is little relationship between reaction and the other three levels of training (Alliger \& Janak, 1989). Amount of learning is most often evaluated via multiple-choice tests. Nevertheless, this approach measures declarative knowledge, an insufficient indicator of behavior. A better indicator of amount of material learned involves assessing procedural knowledge. Nonetheless, there is no established method for assessing procedural knowledge (Haccoun \& Saks, 1998). The most common method for assessing procedural knowledge has been via scenario-based tasks where respondents indicate a likely course of action (Ostroff, 1991). The advantage of this approach is that the answers provided reflect various depths of understanding of the training material.

A common approach used with scenario-based training protocols is to develop self-paced training materials. This approach allows trainees to complete training materials at their own pace. With self-paced materials, trainees typically read an initial orientation to the subject material. This can then be followed by a short knowledge 
appraisal task to ensure comprehension, a component typically reflecting declarative knowledge. Following the introduction, training-specific materials can then be introduced. Application exercises should be included in this portion of the training to allow practice applying newly acquired skills, a component reflecting procedural knowledge. It is essential that feedback be provided with the exercises employed in training. There are several advantages in using this type of approach. One is that it requires little resources beyond the development of the materials. Second, this approach taps both declarative and procedural knowledge. Additionally, providing feedback allows trainees to improve performance.

For the present study, self-paced training materials were developed with some of these factors in mind. Of particular interest were amount of learning and transfer of training. To assess amount of learning, both multiple-choice and a variation of the scenario-based approach were employed. This was done to capture declarative knowledge and allow trainees to practice applying newly acquired skills. There were two variations of the scenario-based approach employed. First, several scenarios were presented with potential answers given as multiple-choice options. Second, new scenarios were presented where the answers provided were, for the most part, open-ended. Upon completion of training, trainees were placed in a situation requiring them to apply the training material.

The purpose of the present study was to answer two broad questions. First, can an interviewer apply truth and deception criteria while conducting an interview? Second, what type of training results in the most gains in performance regarding criteria application? 
Method

Participants

One hundred thirty-eight undergraduates at a southwestern university participated in this study for course credit. There were 55 males and 83 females with ages ranging from 16 to $31(M=19.31, S D=2.19)$ and G.P.A.'s ranging from 2.00 to $4.00(M=3.38$, $S D=0.53)$

\section{General Procedures}

Participants individually completed the experiment in two stages. To begin, participants were given a general description of the experiment during which they were informed (see Appendix A) that they would be serving the role of interviewer in a structured interview. Participants were then asked to read and sign the informed consent form. Next, instructions for all of the covariate measures were given and participants subsequently completed them. Upon completion of the paper and pencil measures, participants began training. This training, presented in a self-paced format, examined the conduct of structured interviewing and deception detection. After completing the requisite training materials participants were taken to an interview room to conduct an interview. The respondent in the interview was a confederate providing scripted responses that were generated to reflect relatively truthful of deceptive statements. The interview was followed by a post-interview questionnaire where participants indicated, among other things, a hiring decision, level of respondent honesty, and usability of the checklist.

Upon completion of the post-interview questionnaire, participants viewed the interview replayed on a television. This was followed by a second post-interview 
questionnaire where participants were allowed to change their hiring decision as well as rate interviewee honesty. The study was a $3 \times 2$ between subjects design with factors of Interview Training (Structured vs. Structured + Deception Detection vs. Structured + Deception Detection + Probe) and Veracity of Interviewee (Truthful vs. Deceptive).

\section{Covariate Materials}

Five covariate measures were completed by each participant: 1) the Wonderlic Personnel Test (Wonderlic, 1992), 2) the Need for Cognition Scale (Cacioppo \& Petty, 1982), 3) the General Learning and Performance Orientation Scale (or mastery motives) (Button, Mathieu, \& Zajac, 1996), 4) Goldberg's Adjective Checklist (Goldberg, 1992), and 5) the Personal Need for Structure Scale (Neuberg \& Newsom, 1993). The measures chosen to serve as covariates were intended to control for relevant characteristics of participants that might contribute to the ability to detect deception during a structured interview. For example, intelligence is an established predictor of many facets of performance. Thus, ability to conduct an interview while attempting to detect deception is likely influenced by intellectual capabilities. Interviewing requires an interviewer to gather, organize, and evaluate information on a candidate. Thus, a person's tendency to organize and evaluate information (i.e., need for cognition) as well as their desire to improve performance and learning new things (i.e., mastery motives) may also relate to the ability to detect deception during an interview. On a similar note, a person's desire to apply heuristics to situations (i.e., need for structure) may also influence deception detection. Finally, personality characteristics may play a role in the ability and willingness to detect deception. Of particular interest are the conscientiousness and 
openness as these two factors have been found to predict performance (Barrick \& Mount, 1991).

Wonderlic Personnel Test (WPT). The WPT is a 50-item measure of general cognitive ability. It is intended to measure, among other things, problem solving, understanding instructions, and ability to apply knowledge to new situations. Typically, the WPT is administered as a timed instrument, allowing 12 minutes for completion. Validity and reliability evidence for the WPT is strong. Correlations with established intelligence tests (e.g. WAIS) are in the .90's (Dodrill \& Warner, 1988). Test-retest reliabilities have ranged from .82 to .94 (Dodrill, 1983) while internal consistency estimates have ranged from .88 to .94 (McKelvie, 1989).

Need for Cognition (NFC). The NFC is an 18-item measure of desire to engage in cognitive tasks. People high in need for cognition are more likely to organize, elaborate, and evaluate information. Half of the items are stated negatively (e.g. "Thinking is not my idea of fun."), and these items are reverse coded for analysis. The other items are positively stated (e.g. "I would prefer complex to simple problems."). Statements are rated on a five-point scale $(1=$ strongly disagree, $5=$ strongly agree $)$ and overall NFC scores are computed by adding each item's rating, with higher scores indicating higher need for cognition. Prior research has established a one-factor solution underlying the NFC scale (Cacioppo, Petty, Feinstein, \& Jarvis, 1996). Additionally, predictive validity has been established with grade point averages, with correlations ranging from .14 to .34 (Cacioppo \& Petty, 1984). Internal consistency estimates are typically greater than .85 (Cacioppo et al., 1996) while (Sadowski \& Gulgoz, 1992)) reported a 7-week test-retest reliability of .88 . For the current study, internal consistency was estimated at .89 . 
Mastery Motives (MM). The MM is an 8-item measure of interest in improving performance and learning new things and was developed to apply across a variety of domains. All of the items reflect a desire to engage in difficult tasks as well as learn new things (e.g. "I try hard to improve on my past performance" and "I prefer to work on tasks that force me to learn new things. Prior research has established the convergent validity of this scale with enjoyment of school work, boredom, and belief in the importance of effort (Jagacinski \& Duda, 2001). Additionally, this scale has demonstrated an acceptable (Anastasi, 1982) level of internal consistency in the literature $(\alpha=.87)$ as well as the current study $(\alpha=.86)$.

Goldberg's Adjective Checklist (GB). The GB is a general personality measure. On this measure people are asked to rate, on a 9-point scale, the extent to which adjectives (100 in all) such as active, fearful, and shy, provide accurate, or inaccurate, self descriptions. Reactions to these adjectives provide measures of emotional stability (neuroticism), intellect (openness), agreeableness, conscientiousness, and surgency (extraversion). This scale has demonstrated consistency and overlap with traditional measures of personality (Goldberg, 1992). Additionally, this scale has demonstrated acceptable levels of internal consistency with subscale $\alpha$ 's ranging from .87 to .90 (Zickar \& Ury, 2002). Consistent with these findings, the current study produced subscale $\alpha$ 's ranging from .83 to .90

Personal Need for Structure (PNS). The PNS is a 12-item scale that assesses an individual's desire for simple structure. People high in need for structure are more likely to lead an organized life, establish and maintain routines, and prefer familiar situations. Eight items reflect a need for structure (e.g. "I enjoy having a clear and structured mode 
of life") while four of the items are reverse coded (e.g. "I'm not bothered by things that interrupt my daily routine"). Statements are rated on a six-point scale ( 1 = strongly disagree, 6 = strongly agree) and overall PNS scores are calculated by averaging each item's rating, with higher scores indicating a higher need for structure. The PNS has demonstrated moderate levels of reliability with $\alpha$ 's ranging from .76 to .85 with an $\alpha$ of .84 for the current study. Additionally, this scale has demonstrated discriminant validity in terms of relationships with other constructs (e.g., need for cognition, intolerance, etc.) and convergent validity based on relationships with specific personality constructs (e.g., openness and conscientiousness) (Neuberg \& Newsom, 1993).

\section{Training Materials}

To prepare participants for conducting the interview several training modules were developed. These modules trained participants in conducting structured interviews, deception detection via criteria checklist, and deception detection via checklist and using probe questions. Each training module began with a basic description of the relevant principles for each module. This was followed by a general knowledge appraisal task consisting of multiple-choice items regarding the training material. Following the knowledge appraisal task were application problems where participants applied the newly acquired information.

Structured Interview Training. The first training module, completed by all participants, focused on structured interview training (see Appendix B). This training module was developed using standard structured interview procedures and recommendations (Campion, Palmer, \& Campion, 1997; Jackson, 2001). The structured interview training module began with an introduction to basic structured interviewing 
principles and techniques, including a description of structured interviews, strengths and weaknesses, and do's and don'ts. This was followed by a knowledge appraisal task requiring participants to answer multiple-choice questions regarding structured interviews. These questions focused on the content presented in the training material (e.g., "The general purpose of an interview is to:"). Following knowledge appraisal, participants were presented with a target job (e.g. secretary) and three appropriate job dimensions (e.g. multitasking). Each of these dimensions was accompanied by an example interview question. Following the examples, participants were given two new job dimensions and asked to generate one interview question for each dimension. This task was repeated three times for a total of four exercises.

Deception Detection Training. The second training module, completed by twothirds of the participants, focused on deception detection (see Appendix C). This training began with a description of the prevalence of deception during employment interviews as well as the importance of hiring honest people. Following this overview, participants were introduced to the concept of applying criteria to verbal statements in an attempt to detect deception. Each criterion was then presented with a definition, rational, and example statements demonstrating manifestation of the criterion. The definitions, rationales, and example statements were obtained or developed from training materials used by (Connelly et al., 2003) to train raters (a more thorough discussion of the criteria appears in a later section). This was followed by a knowledge appraisal task requiring participants to answer multiple-choice questions regarding deception detection. These questions focused on the definitions of the criteria (e.g., "Statements with relatively few self-references are indicative of which criterion?"). Following the knowledge appraisal 
task, participants completed four exercises that required reading a sample statement and indicating, via multiple-choice, which criteria were present in the statement. Each exercise was accompanied by an answer key that indicated why relevant criteria were present in the statement as well as why irrelevant criteria were not present. This was done to ensure that training involved the opportunity to practice as well as feedback regarding performance (Frank \& Feeley, 2003). Following the multiple-choice component of criteria application, the criteria list was presented and participants were required to read six additional statements and indicate which criteria were present in each statement. This was an open-ended task in that participants were required to indicate criteria from the entire list rather than from multiple-choice items. As before, each exercise was accompanied by an answer key indicating which criteria were present in the statement.

Probe Question Training. The final training module, completed by one-third of the participants, focused on the use of probe questions (see Appendix D). Probe training began with the purpose and usefulness of using probe questions during structured interviews. During training, participants were exposed to four strategies to forming probe questions. These strategies were developed to reflect strategies used by general interviewers as well as interrogators (Elaad, 2003). The first strategy, additional information, consisted of obtaining additional information (e.g." "Tell me more about that situation"), while the second strategy, inconsistency, involved asking probe questions that are inconsistent with a given statement (e.g., "It is unusual for a non-employee to solve such a problem, why were you asked to do it?'). The inconsistency approach is most similar to the approach typically taken in interrogation contexts. The third strategy, expansion, required asking questions to allow respondents to expand their statements 
(e.g., "Please tell me more"). The expansion strategy differs from the additional information strategy in that the probe questions are not specific to the response as in the additional information strategy. The final strategy, interference, required interviewers to ask questions that interfere with the flow of responding (e.g., after response regarding a technically detailed question, the interviewer might ask, "Describe how you have handled conflict at home"). Questions formed using this approach are irrelevant to the given statement or question. In addition to these strategies, participants were informed that it is not always necessary to ask a probe question.

Following the presentation of the strategies was a knowledge appraisal task requiring participants to answer multiple-choice questions regarding probe questions. These questions focused on the content presented in training with an emphasis on the probe-question strategies (e.g., "Which strategy requires an interviewer to understand what typically happens in a given situation?"). Following the knowledge appraisal task, participants were presented with an open-ended list containing four probe questions for each strategy. More specifically, each probe question consisted of a general question structure with one or two places to insert a relevant remark (e.g., "I find ___ interesting. Could you tell me more information about that?'). Participants used this list to complete six exercises consisting of an interview question, the resulting response, and the appropriate probe strategies to use. Participants were then required to form one probe question for each relevant strategy. Accompanying each exercise was an answer key explaining why the indicated strategies were useful, why the other strategies were not useful, and a potential probe question for each relevant probe question. 
Upon completion of training, all participants were informed they would be interviewing an individual using the techniques described during training. They were also informed they would be completing a questionnaire, after the interview, requiring them to indicate a hiring decision regarding the interviewee in addition to several questions regarding interviewee honesty and usability of the checklist. Participants were then given the interview questions and the list of criteria (see Appendix E) to look for during the interview and subsequently conducted the interview. Although participants receiving only structured interview training were not exposed to the criteria they were given the list of criteria to use during the interview. This was done to examine whether specific criteria training improved participants' ability to use the criteria during the interview. Thus, the structured interview training only group served as the baseline for detecting deception during a structured interview. Additionally, participants receiving probe question training were given the list of open-ended probe questions (see Appendix E) before conducting the interview.

\section{Interview Veracity}

In an effort to ensure that criteria were present in statements given by the interviewee, two scripts were developed to reflect the criteria and were memorized by research assistants (confederates) involved in data collection. One script, reflecting "truthful" statements (see Appendix F), contained 16 truth and 7 deception criteria. The other script, reflecting "deceptive" statements (see Appendix G), contained 8 truth and 16 deception criteria. Scripts were generated, in part, using statements obtained from a study where participants were instructed to either entirely relay the truth or completely fabricate their responses (Connelly et al., 2003). Statements obtained from truthful reports as well 
as three levels of deceptive reports were examined. After reviewing these statements, typical trends and speech structure were used to generate statements for the scripts used in this study. These statements were used to ensure that statements generated for the script sounded realistic rather than artificial. In addition to generating realistic statements, it was important to develop scripts containing both truth and deception criteria.

A script consisting of only truth or deception criteria would not be highly realistic. Additionally, such scripts would result in easy detection for participants. Thus, to establish external and face validity, both scripts were generated reflecting a ratio of roughly 2 to 1 criteria. Using such a ratio gives participants enough cues to make the correct decision while maintaining a level of difficulty so as not to be too blatant. To ensure the scripts contained these criteria, raters not involved in data collection, and blind to the conditions, rated each statement for the presence of criteria. These ratings indicated that the intended criteria were present in each statement ( $88 \%$ agreement). Rater disagreement occurred only with criteria reflecting abstract concepts (e.g., goals). Additionally, all of the criteria were indicated as present by at least one of the raters, with 19 of the 23 criteria in the truth script identified by all raters and 21 of the 24 criteria in the deception script identified by all raters.

\section{Confederate Training}

To ensure the criteria were present in the responses and to maintain consistency across interviews, research assistants (confederates) were used as interviewees for this experiment. Several weeks before data collection began each assistant was given training regarding the scripts. To begin, assistants were given a basic understanding of the current research project as well as an understanding of research leading up to the criteria list used 
for this experiment. This was followed by the rational for using prefabricated answers in the interviews. Both scripts and the criteria were then given to the assistants and they were instructed to memorize the responses in the scripts. In memorizing the scripts, an emphasis was put on consistency in responding. Assistants were informed that it was more important they were consistent in the interview than they had the script memorized verbatim. However, there were several important aspects of the scripts (i.e., those reflecting specific criteria) to relay as accurately as possible. Thus, they were to use the criteria list to ensure specific criteria were reflected in the statements. In addition to the scripts, the assistants were presented with the training materials to give them an idea of what the participants would experience. Following data collection, the interviews were rated for consistency and realism by coders not involved in the data collection phase. This was done to ensure the responses given by confederates were consistent across interviews as well as realistic.

\section{Criteria Checklist}

Criteria comprising the checklist were obtained from a larger criteria list created for detecting deception (Connelly et al., 2003). In this study, participants in a mock job interview were instructed to either completely tell the truth or to fabricate their answers to varying degrees, ranging from distorting information to complete fabrication. Responses obtained in this study were rated using a set of 196 criteria, generated by the researchers, intended to detect truth and deception in verbal statements. Using these criteria in discriminant function analyses produced classification rates ranging from $70.2 \%$ to $90.2 \%$ with an average rate of $79.9 \%$ classification. Additionally, 64 criteria were highly related to the discriminating function. Based on these analyses, 16 criteria ( 8 truth and 8 
deception) were chosen based on canonical loadings with a truth-fabrication function. Criteria were selected that exhibited high loadings $(>.20)$ for multiple truth-fabrication comparisons (e.g., truth vs. fabrication and truth vs. distortion). Additionally, criteria that involved grammatical structure of statements were excluded (e.g., Infrequent use of adverbs). Rather than employ the entire list of discriminating criteria, 16 were chosen in part to reduce the cognitive load of the participants. It is unlikely that an individual could effectively use a checklist consisting of 64 criteria while conducting an interview. Additionally, criteria were chosen that could easily be embedded within prefabricated interview responses designed to contain these criteria.

\section{Procedure}

The experiment was completed by participants individually in two stages. The first stage involved the completion of the covariate and training materials. Upon completion of the covariate measures, participants were given the Structured Interview Training module and instructed to read the material and complete the accompanying exercises. Upon completion of the first training module, the experimenter examined the responses to the exercises to ensure all items were completed. Participants receiving structured interview training only were then taken to the interview room to conduct the interview. Participants receiving further training were then given the Deception Detection Training module. Again, upon completion the experimenter ensured all items were completed. Participants concluding training were then taken to the interview room to conduct the interview. Finally, the remaining participants were given the Probe Question Training module and the experimenter ensured all items were completed before moving on the interview. 
The second stage of the experiment involved the interview and post-interview tasks. To begin, participants were given the interview questions and criteria checklist (and probe questions for those receiving probe training) and instructed to ask the questions in the order they were presented. Second, participants were instructed to listen to the response while noting which criteria were present in the statements. Participants were informed that it was appropriate for them to pause after each response to ensure they had adequate time to go through the criteria list. To begin the interview, participants were introduced to the interviewee (a confederate). The experimenter activated a video camera to record the interview and subsequently exited the room. During the interview, participants asked each question, in order, and as the respondent spoke, noted any criteria present in each statement. Additionally, participants given probe question training asked probe questions as they felt necessary. Upon completion of the interview, the experimenter deactivated the camera and removed the videotape.

Once the interview was completed, participants completed the first post-interview questionnaire (see Appendix $\mathrm{H}$ ) indicating, among other things, a hiring decision, how quickly a decision was reached, how confident they felt about the decision, level of respondent honesty and deception, and usability of the checklist. After completing the post-interview questionnaire, participants viewed the entire interview replayed on a television. While watching the interview, participants noted any additional criteria they may have missed during the interview. After viewing the interview, participants completed the second post-interview questionnaire (see Appendix I) indicating, among other things, level of respondent honesty and deception as well as number of additional criteria checked. In addition to these ratings, the second post-interview questionnaire 
gave participants the opportunity to change their hiring decision. Participants changing their decision were asked to indicate why they did so in addition to listing any criteria that led them to change their decision. Upon completion of the post-interview questionnaires participants were debriefed and the experiment was concluded.

\section{Results}

Table 1 presents descriptive statistics and reliability coefficients obtained for each of the covariates. Before conducting analyses, the interviews were coded for the gender of the interviewer and interviewee, providing an indicator of gender mix (e.g., same sex male, mixed female interviewer, etc.). The gender mix variable was subsequently used as a covariate for analyses. In addition to the dependent variables from the post-interview questionnaire, several dependent variables were also created. To create these variables, the checklists used by each participant were coded for number of truth criteria checked, number of deception criteria checked, number of criteria correctly checked, and number incorrectly checked. This coding resulted in markers of number of truth and deception criteria checked, number of criteria correct, and number of criteria incorrect during the interview as well as number of truth and deception criteria, and number correct and incorrect during the videotape review. This resulted in 17 continuous dependent variables available for ANCOVA's. It is important to note that number correct and incorrect are not symmetrical (or inversely related) measures. That is, a high score on number of criteria correct does not require a low score on number of criteria incorrect. It is possible to have both a large number correct and incorrect. 
Table 1

Descriptive Statistics and Reliability Coefficients for the Covariate Measures

\begin{tabular}{lcccc}
\hline & $\mathrm{N}$ & $\alpha$ & $M$ & $\mathrm{SD}$ \\
\hline Wonderlic Personnel Test & 138 & - & 24.23 & 4.98 \\
Need for Cognition & 138 & .89 & 3.37 & 0.62 \\
Personal Need for Structure & 138 & .84 & 3.40 & 0.78 \\
Mastery Motives & 138 & .86 & 5.68 & 0.77 \\
Goldberg Scales & & & & \\
$\quad$ Intellect & 137 & .86 & 6.62 & 0.86 \\
$\quad$ Emotional Stability & 137 & .83 & 5.12 & 0.95 \\
Conscientiousness & 137 & .88 & 6.46 & 0.93 \\
$\quad$ Agreeableness & 137 & .89 & 7.00 & 0.85 \\
Surgency & 137 & .90 & 6.09 & 1.06 \\
\hline
\end{tabular}




\section{Covariates}

A two by three ANCOVA indicated that all of the covariates, with the exception of mastery motives, conscientiousness, and agreeableness, were significant for at least one of the seventeen dependent variables. However, as shown in Table 2, the majority of the covariates influenced number of criteria checked as well as criteria correct and incorrect during the interview and video review. In particular, the most influential covariates were gender mix, surgency (extraversion), and intelligence (WPT).

Gender mix was a significant covariate for level of honesty and level of deception following the video, number of truth criteria checked during the interview and video review, and number of criteria correct and incorrect during both the interview and video review. When rating honesty, females interviewing another female provided lower ratings than all other combinations. When rating deception, females interviewing another female provided higher ratings than males and females interviewing another male. Apparently, female participants viewed female interviewees as least honest and most deceptive, regardless of actual message veracity. All other findings with respect to gender mix showed a similar pattem, that is, females interviewing another female were different from the other combinations, with the exception of criteria incorrect during the interview where males interviewing another male got more incorrect than all other combinations.

In addition to these findings, intelligence and surgency were moderately influential covariates. It is not surprising that intelligence was positively related to number of criteria correct during the video and negatively related to criteria incorrect during the interview. Regarding surgency, those lower in extraversion were quicker to make their decisions and more confident in them. 
Table 2

Covariate Effects

\begin{tabular}{|c|c|c|c|c|c|}
\hline & $M S$ & MSe & $F$ & $\eta$ & Influence \\
\hline \multicolumn{6}{|l|}{ Wonderlic Personnel Test } \\
\hline Level of Honesty after Interview & 7.04 & 1.40 & $5.04^{*}$ & .20 & - \\
\hline \# Criteria Incorrect During Interview & 81.45 & 19.14 & $4.26^{*}$ & .18 & - \\
\hline \# Criteria Correct During Video & 75.85 & 14.69 & $5.16^{*}$ & .20 & + \\
\hline \multicolumn{6}{|l|}{ Need for Cognition } \\
\hline \# of Additional Criteria Checked & 30.39 & 7.21 & $4.21 *$ & .18 & - \\
\hline \# Criteria Correct During Video & 92.94 & 14.69 & $6.32 *$ & .22 & + \\
\hline \multicolumn{6}{|l|}{ Personal Need for Structure } \\
\hline Level of Honesty after Interview & 6.88 & 1.40 & $4.93^{*}$ & .20 & - \\
\hline \multicolumn{6}{|l|}{ Intellect } \\
\hline \# Criteria Correct During Video & 65.63 & 14.69 & $4.47^{*}$ & .19 & - \\
\hline \multicolumn{6}{|l|}{ Emotional Stability } \\
\hline \# Criteria Correct During Interview & 63.70 & 16.13 & $3.95^{*}$ & .18 & - \\
\hline \# Criteria Correct During Video & 62.90 & 14.69 & $4.28^{*}$ & .18 & - \\
\hline \multicolumn{6}{|l|}{ Surgency } \\
\hline Level of Honesty after Interview & 8.11 & 1.40 & $5.80^{*}$ & .21 & - \\
\hline Quickness of Decision & 13.82 & 1.50 & $9.23 * *$ & .26 & - \\
\hline Confidence in Decision & 12.25 & 1.17 & $10.49^{* *}$ & .28 & - \\
\hline \# Deception Criteria During Interview & 83.91 & 15.44 & $5.43^{*}$ & .21 & + \\
\hline \# Deception Criteria During Video & 93.48 & 20.72 & $4.51^{*}$ & .19 & + \\
\hline \multicolumn{6}{|l|}{ Gender Mix of Interview } \\
\hline Level of Honesty after Video & 8.39 & 1.92 & $4.36^{*}$ & .19 & A \\
\hline Level of Deception after Video & 5.06 & 0.73 & $6.92 *$ & .23 & $\mathrm{D}$ \\
\hline \# Truth Criteria During Interview & 191.60 & 28.81 & $6.65^{*}$ & .23 & B \\
\hline \# Truth Criteria During Video & 265.51 & 29.52 & $9.00 * *$ & .26 & $\mathrm{C}$ \\
\hline \# Criteria Correct During Interview & 82.42 & 16.13 & $5.11^{*}$ & .20 & $\mathrm{~B}$ \\
\hline \# Criteria Incorrect During Interview & 133.07 & 19.14 & $6.95 * *$ & .23 & $\mathrm{E}$ \\
\hline \# Criteria Correct During Video & 76.27 & 14.69 & $5.19^{*}$ & .20 & $\mathrm{C}$ \\
\hline \# Criteria Incorrect During Video & 143.06 & 22.94 & $6.24 * *$ & .22 & B \\
\hline
\end{tabular}

Note: $\eta=$ square root of partial effect size. Degrees of freedom for all analyses $=1,122$.

$* p<.05$

$* * p<.01$

A: Female interviewing female lower than all others

$B$ : Female interviewing female lower than male interviewing male

$\mathrm{C}$ : Female interviewing female lower than male interviewing male and female interviewing male

D: Female interviewing female higher than male interviewing male and female interviewing male

E. Male interviewing male more than all others 


\section{Criteria Accuracy}

To address accuracy, the application of the criteria was examined, including number checked during the interview and during the video review as well as number correct and incorrect during both the interview and the video review. Table 3 presents significant effects only for all analyses (see Appendix $J$ for full ANOVA tables and Appendix $\mathrm{K}$ for covariate-adjusted descriptive statistics). As expected, there was an effect for interview veracity on number of truth, $F(1,122)=12.81, p<.01$, and deception criteria checked during the interview, $F(1,122)=43.81, p<.01$, and the video review, $F(1,122)=12.83, p<.01$, and, $F(1,122)=41.15, p<.01$, respectively. There were no differences between number of criteria checked during the interview and number checked during the video review. Across training types, participants interviewing truthful respondents checked more truth criteria, and fewer deception criteria during the interview $\left(M_{T C r i t}=13.85, S D=5.97 ; M_{D C r i t}=5.10, S D=3.50\right)$ than participants interviewing deceptive respondents $\left(M_{T C r i t}=9.72, S D=5.11 ; M_{D C r i t}=9.48, S D=4.65\right)$. A similar pattern of results occurred for criteria checked during the video review. 
Table 3

Overall Training and Veracity Effects

\begin{tabular}{|c|c|c|c|c|}
\hline & $M S$ & MSe & $F$ & $\eta$ \\
\hline \multirow{2}{*}{\multicolumn{5}{|c|}{ Deception Detection vs. Probe Questions) }} \\
\hline & & & & \\
\hline Level of Deception after Interview & 4.16 & 0.79 & $5.28 * *$ & .28 \\
\hline Difficulty of Checklist & 7.51 & 1.82 & $4.13^{*}$ & .25 \\
\hline Level of Deception after Video & 2.94 & 0.73 & $4.02 *$ & .25 \\
\hline \# Truth Criteria During Interview & 160.13 & 28.81 & $5.56 * *$ & .29 \\
\hline \# Deception Criteria During Interview & 106.48 & 15.44 & $6.89 * *$ & .32 \\
\hline \# Truth Criteria During Video & 100.89 & 29.52 & $3.42 *$ & .23 \\
\hline \# Deception Criteria During Video & 97.41 & 20.72 & $4.70 *$ & .27 \\
\hline \# Criteria Correct During Interview & 136.12 & 16.66 & $8.17 * *$ & .34 \\
\hline \# Criteria Incorrect During Interview & 64.12 & 19.14 & $3.35^{*}$ & .23 \\
\hline \# Criteria Correct During Video & 46.04 & 14.69 & $3.14^{*}$ & .22 \\
\hline \# Criteria Incorrect During Video & 121.23 & 22.94 & $5.29 * *$ & .28 \\
\hline \multicolumn{5}{|l|}{ Interview Veracity (Truth vs. Deception) } \\
\hline Level of Honesty after Interview & 31.75 & 1.40 & $22.74 * *$ & .40 \\
\hline Level of Deception after Interview & 5.68 & 0.79 & $7.21 * *$ & .24 \\
\hline Quickness of Decision & 36.41 & 1.50 & $24.32 * *$ & .41 \\
\hline Confidence in Decision & 19.48 & 1.17 & $16.68 * *$ & .35 \\
\hline How much did you like interviewee & 8.68 & 0.99 & $8.77 * *$ & .26 \\
\hline Level of Honesty after Video & 38.64 & 1.92 & $20.09 * *$ & .38 \\
\hline Level of Deception after Video & 9.79 & 0.73 & $13.39 * *$ & .31 \\
\hline \# of Additional Criteria Checked & 54.04 & 7.21 & $7.49 * *$ & .24 \\
\hline \# Truth Criteria During Interview & 369.18 & 28.81 & $12.81 * *$ & .31 \\
\hline \# Deception Criteria During Interview & 676.65 & 15.44 & $43.81 * *$ & .51 \\
\hline \# Truth Criteria During Video & 378.70 & 29.52 & $12.83^{* * *}$ & .31 \\
\hline \# Deception Criteria During Video & 852.43 & 20.72 & $41.15 * *$ & .50 \\
\hline$\%$ Criteria Correct During Interview & 686.67 & 14.69 & $4.20 *$ & .18 \\
\hline
\end{tabular}

Note: $\eta=$ square root of partial effect size. Degrees of freedom for training analyses = 2,122 and for veracity analyses $\mathrm{d} f=1,122$.

$* p<.05$

$* * p<.01$ 
More important than the veracity of the interview was the question of whether training led to improved performance. As seen in Table 3, there was a training effect for all of the criteria variables. In particular, participants receiving deception training $(M=$ $14.88, S D=3.98)$ got more criteria correct during the interview than participants receiving structured interview training $(M=12.66, S D=4.29)$ and those receiving probe training $(M=11.44, S D=4.04), F(2,122)=8.46, p<.01$. Additionally, when reviewing the video, deception detection participants $(M=16.05, S D=4.41)$ again got more criteria correct, $F(2,122)=3.14, p<.05$, than structured interview participants $(M=$ $14.13, S D=4.03)$, although probe question participants $(M=14.54, S D=3.78)$ were not different from either group. Examination of number of criteria correct during the interview and video review revealed that only deception detection participants significantly improved their performance, $F(2,122)=5.62, p<.01$.

In addition to number correct, structured interview participants $(M=7.14, S D=$ 4.61) got more criteria incorrect during the interview than probe question participants ( $M$ $=4.75, S D=4.58), F(2,122)=3.35, p<.05$. Deception detection participants $(M=6.34$, $S D=4.08$ ) were not different from the other training groups. When reviewing the video, structured interview $(M=9.21, S D=4.94)$ and deception detection participants $(M=$ $8.09, S D=5.78)$ got more criteria incorrect than probe question participants $(M=5.91$, $S D=3.97), F(2,122)=5.29, p<.01$. There were no differences in number of criteria incorrect between the interview and video review. Clearly, receiving training specific to the criteria results in superior application of the criteria relative to no specific criteria training. 
However, number correct and incorrect is dependent upon the total number of criteria checked. Thus, it is possible to attain a high number correct simply by checking a large number of criteria (which would also result in a high number incorrect). To account for this, percentage correct and incorrect, relative to number checked, were calculated. Using percentages, there was a training effect for percent correct during the interview, $F(2,122)=4.35, p<.05$ and percent correct during the video, $F(2,122)=8.38, p<.01$. Specifically, for percent correct during the interview and during the video, deception detection $(M=.72, S D=.11$ and $M=.69, S D=.13$, respectively) and probe question participants $(M=.74, S D=.16$, and $M=.73, S D=.14$, respectively) outperformed structured interview participants $(M=.66, S D=.11$, and $M=.62, S D=.12$, respectively). These results suggest that criteria training results in superior performance to no training.

In addition to the training effect, there was an interview veracity effect for percent correct during the interview, $F(1,122)=4.20, p<.05$. In particular, participants interviewing deceptive respondents $(M=.73, S D=.14)$ outperformed those interviewing truthful respondents $(M=.68, S D=.13)$. This pattern of results may indicate that participants were better able to use the deception criteria.

Nevertheless, while probe question participants achieved similar levels of performance regarding percent correct, deception detection participants correctly identified more criteria (see Figures 3 through 6). It is unclear why probe training resulted in reduced performance regarding criteria correctly identified. Potentially, these participants were under greater cognitive demand (Gilbert, Pelham, \& Krull, 1988) due to the formulation of probe questions resulting in reduced ability to apply the criteria. This 
conclusion is supported by the fact that probe-training participants $(M=5.14, S D=1.35)$ indicated the criteria checklist was more difficult to use than did structured interview participants $(M=4.30, S D=1.45)$ although deception detection participants did not differ from either group $(M=4.74, S D=1.08), F(2,122)=4.13, p<.05$. Alternatively, the use of probe questions may have facilitated a relationship between the participant and respondent as a result of considering each response and formulating questions related to the responses. 


\section{Figure 3}

Number of criteria correct during the interview

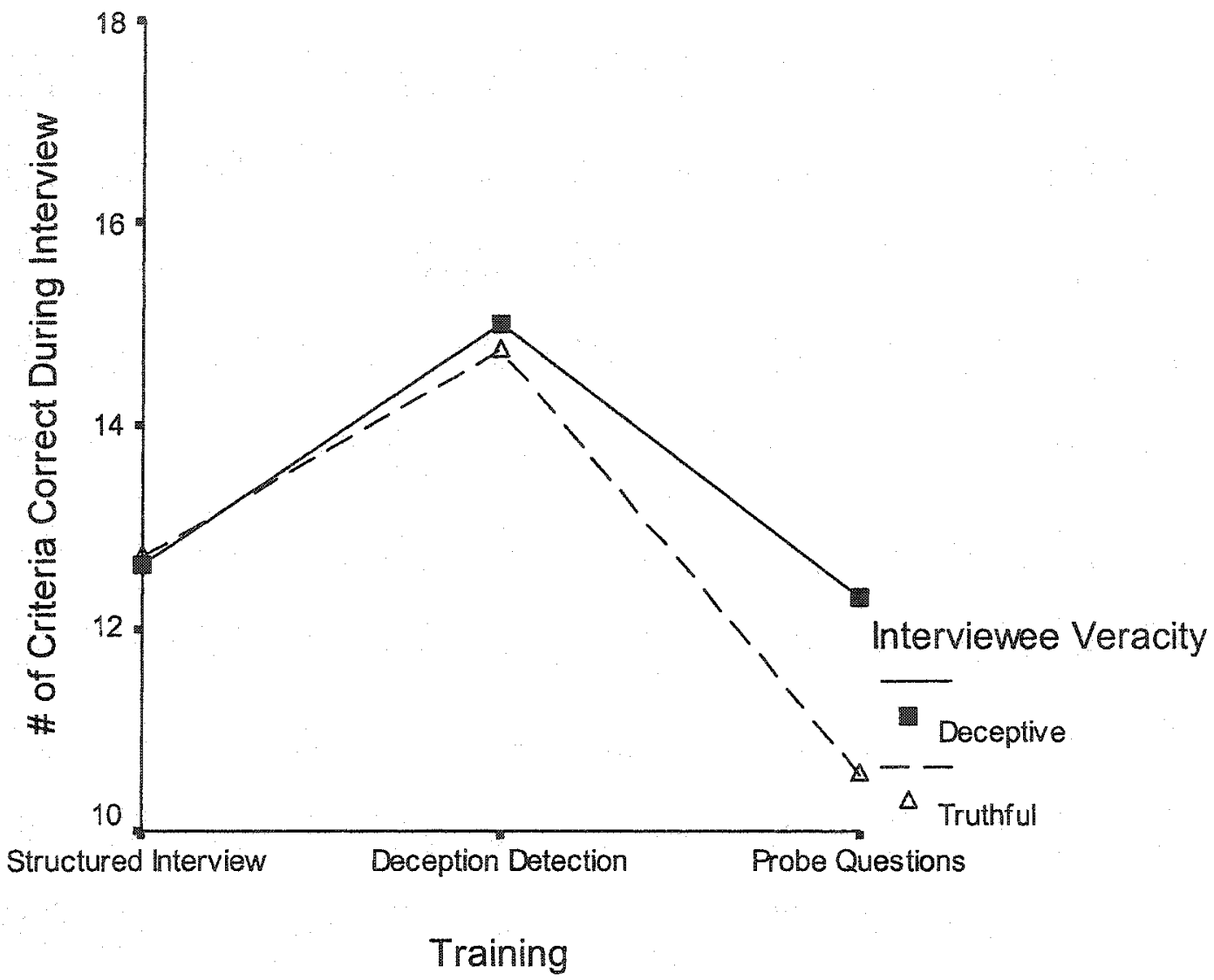




\section{Figure 4}

Percent correct during the interview

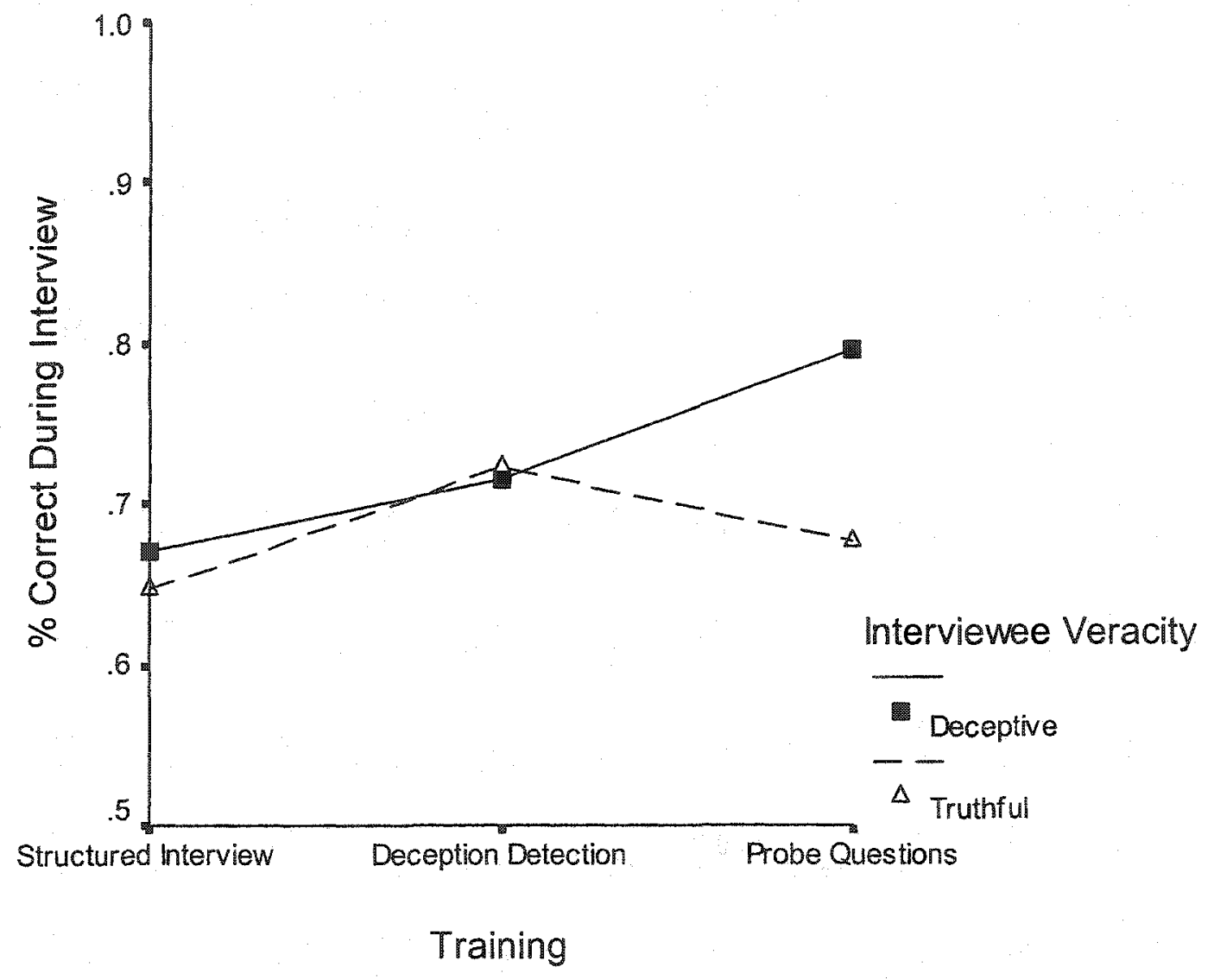




\section{Figure 5}

Number of criteria correct during the video review

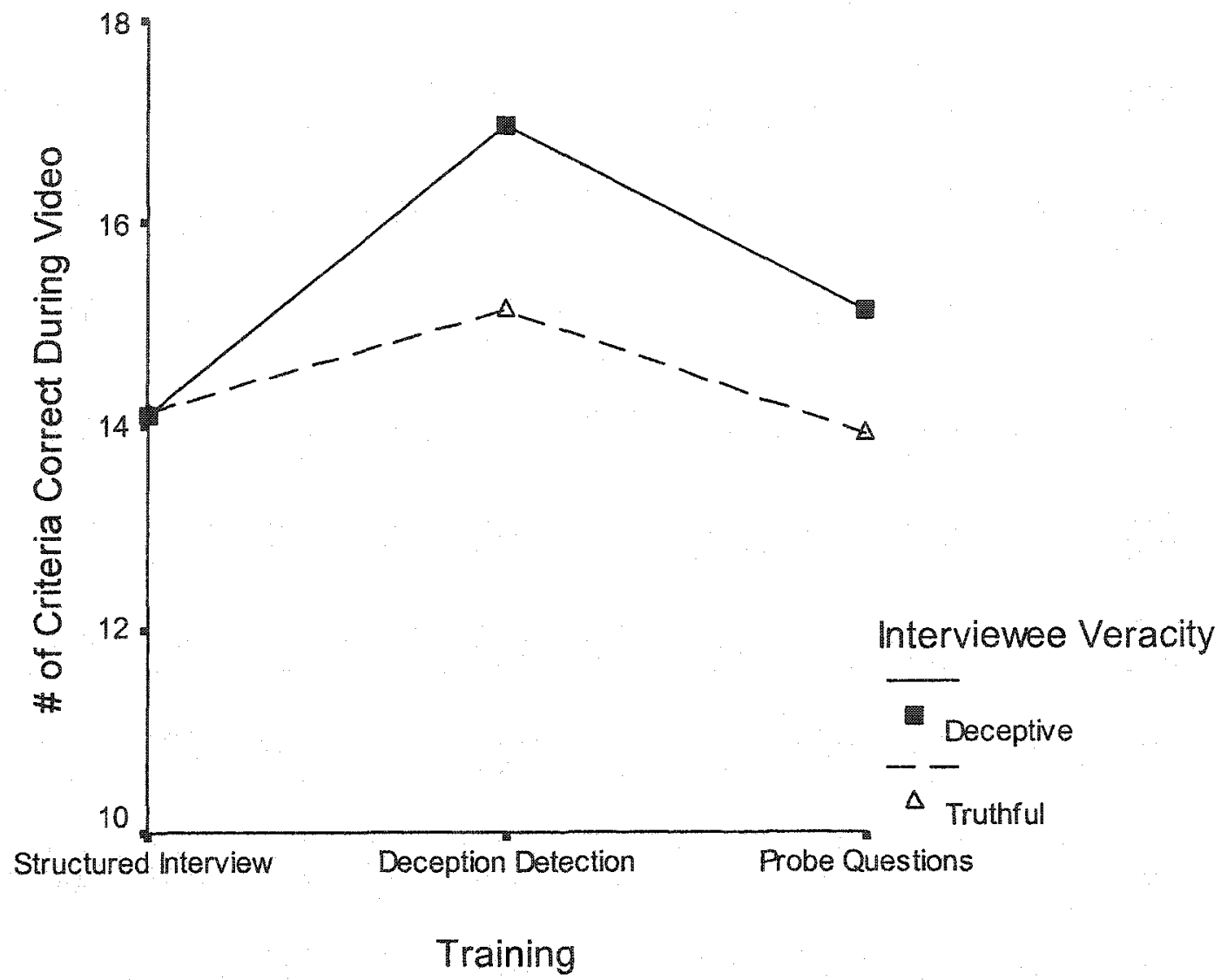


Figure 6

Percent correct during the video review

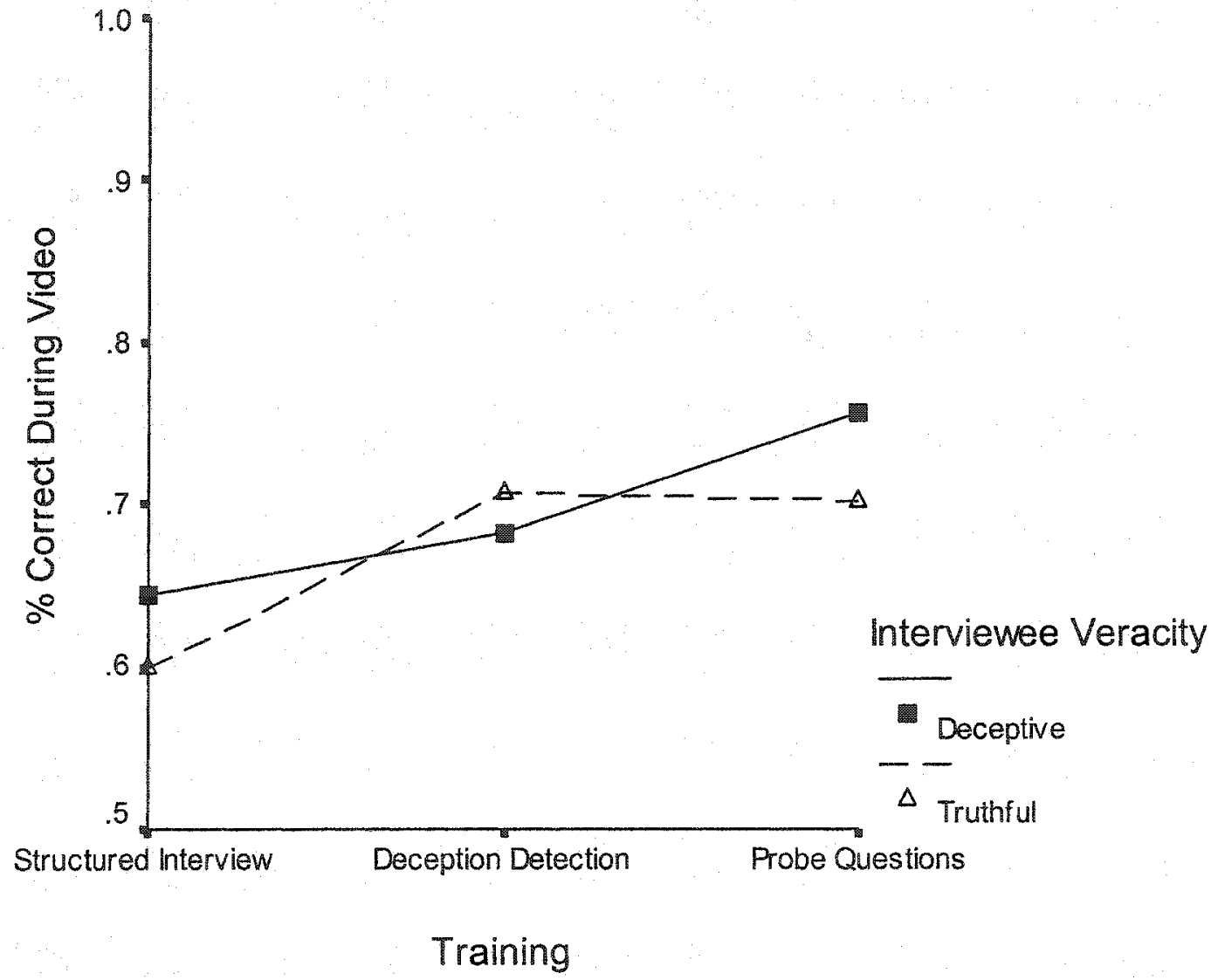


In addition to the training effects for number of criteria correct, there was an effect on the number of truth criteria checked during the interview, $F(2,122)=5.56, p<$ .01 , and during the video review, $F(2,122)=3.42, p<.05$. However, these results must be interpreted cautiously as the effect ignores interview veracity. Nevertheless, during the interview, more truth criteria were checked by structured interview participants ( $M=$ $13.49, S D=6.77)$ and deception detection participants $(M=12.16, S D=4.41)$ than by probe question participants $(M=9.69, S D=5.82)$. During the video review, structured interview participants $(M=15.04, S D=6.87)$ again checked more truth criteria that did probe question participants $(M=12.01, S D=5.73)$. Deception detection participants did not differ from either group $(M=13.25, S D=5.09)$. Similar effects occurred when examining number of deception criteria checked during the interview, $F(2,122)=6.89, p$ $<.01$, and during the video review, $F(2,122)=4.70, p<.05$. Specifically, deception detection participants checked more deception criteria during the interview $(M=9.06, S D$ $=4.51)$ and during the video review $(M=10.90, S D=5.62)$ than both structured interview participants $(M=6.30, S D=4.85 ; M=8.30, S D=5.62$, respectively $)$ and probe question participants $(M=6.50, S D=4.31 ; M=8.43, S D=4.32$, respectively). Although, in all cases, the number of criteria checked increased from the interview to the video review, none were significant. In general, deception detection participants checked fewer truth criteria and more deception criteria, suggesting that deception training may reduce truth bias. 


\section{Overall Judgments}

Because veracity was manipulated in this study, examination of ratings of honesty and deceptiveness provided a manipulation check. As shown in Table 3, there was an interview veracity effect for honesty, $F(1,122)=22.74, p<.01$, and deception ratings after the interview, $F(1,122)=7.21, p<.01$, and after the video review, $F(1,122)=$ $20.09, p<.01$, and $, F(1,122)=13.39, p<.01$, respectively. In fact, across training types, honesty ratings following the interview were always greater, and deception ratings following the interview always lower, for truthful respondents $\left(M_{\text {Truth }}=5.85, S D=0.98\right.$; $\left.M_{\text {Deception }}=2.10, S D=0.96\right)$ than for deceptive respondents $\left(M_{\text {Truth }}=4.73, S D=1.41\right.$; $M_{\text {Deception }}=2.57, S D=0.85$ ). Note, truth ratings were on a seven-point scale while deception ratings were on a five-point scale. This pattern of results indicates that the scripts presented relatively truthful and deceptive accounts (based on the criteria) as intended. More centrally, these results may suggest that the criteria can be successfully applied in an interview context.

In addition to honesty and deception ratings, there was an interview veracity effect for likeability of the respondent, $F(1,122)=8.77, p<.01$, quickness of decision, $F(1,122)=24.32, p<.01$, and confidence in decision, $F(1,122)=16.68, p<.01$. In particular, participants interviewing truthful respondents $(M=5.47, S D=1.02)$ indicated more liking for the respondent than did participants interviewing deceptive respondents $(M=4.95, S D=0.99)$. Additionally, under the truthful condition, participants were more confident in their decisions $(M=5.63, S D=0.96)$ and reached them quicker $(M=5.00$, $S D=1.19)$ than participants under deceptive condition $(M=4.85, S D=1.25 ; M=3.90$, $S D=1.30$, respectively) 
Regarding training, there was a significant effect for deception ratings after the interview, $F(2,122)=5.28, p<.01$, and for deception ratings following the video review, $F(2,122)=4.02, p<.05$, but not for either honesty rating. There were no differences between the post-interview and post-video ratings of honesty and deception. When rating deception immediately following the interview, participants receiving deception training provided higher deception ratings $(M=2.68, S D=0.95)$ than both structured interview $(M=2.23, S D=1.04)$ and probe question training $(M=2.09, S D=0.77)$ participants. When rating deception following the video review, participants receiving deception training again provided higher deception ratings $(M=2.73, S D=0.98)$ than participants receiving structured interview training $(M=2.33, S D=0.80)$ and probe training $(M=$ $2.27, S D=0.95$ ). What is of note is that this pattern of effects for training, with respect to judgment criteria, is similar to that for evaluations regarding the accuracy of criteria identified, suggesting that the criteria were applied in decision making.

\section{Discussion}

Before turning to the broader conclusions, certain limitations of the present study should be noted. First, it was necessary to use an experimental design to manipulate and control the veracity and content of the interviews. Although use of an experimental design offers advantages with respect to control, different findings may emerge in a study using an actual job interview. On the other hand, conducting a field study would result in markedly different interview responses across interviews. As a result, it is possible that some or many of the criteria would not appear in statements obtained during the 
interviews. While this is not a problem in real-world settings, it would make testing the applicability of this subset of criteria somewhat difficult.

Along similar lines, the interviewers in this study had no prior experience in conducting interviews. While interviewing itself is not a complex task, the act of conducting quality interviews is something that is learned through experience. As a result, conducting a study with experienced interviewers may produce different results, although there is nothing in the current results to suggest that lack of experience adversely affected the outcomes. Nevertheless, the goal of the present study was not to examine interviewing skills per se, but rather to examine if the criteria could be applied during an interview.

Bearing these limitations in mind, the present study resulted in some noteworthy findings regarding the detection of deception. To begin, it appears that the criteria worked from a practical standpoint. In general, participants were able to apply the criteria while conducting the interview. Criteria training resulted in ten percent gains in accuracy over those not receiving training. Assuming a base rate of 50 percent correct, these increases are substantial.

Although probe training resulted in similar performance in terms of percent correct, these participants did not use the criteria checklist as much as other participants. In fact, probe question participants checked fewer criteria in general (consequently, they were less likely to get more criteria correct or incorrect). Thus, the use of probe questions may have limited the ability to attend to the criteria because of cognitive demand. This finding is consistent with findings from cognitive demand and decision-making research where cognitive demand reduces quality of judgments (Gilbert et al., 1988). There are 
several ways to deal with the reduction in performance due to cognitive demand. One would be to require that interviewers be experts regarding the criteria. Expertise would reduce cognitive load and allow more resources for forming probe questions. A second approach would require that people be extensively trained with the criteria and in the use of probe questions. However, it is unclear what the gains would be relative to the cost of additional training. These are issues worth addressing in future research.

It is interesting to note that, although only a marginal effect, for participants using probe questions, accuracy was greater when receiving deceptive statements than those receiving truthful statements (see Figure 4). Again, it is likely that cognitive demand played a role in the diminished accuracy for probe question participants. However, it is possible that the use of probe questions may be more useful when the respondent is deceptive. Thus, while deception detection rates often range from .50 to .70 , the use of probe questions could raise accuracy to .80 or more for deceptive respondents. This is particularly important in light of the fact that most research has demonstrated that deceptive statements are often classified at less than chance rates (Levine et al., 1999). However, as previously mentioned, a reduction in cognitive load would be necessary to conduct interviews using probe questions. This is an area that deserves additional research because of the potential impact of this finding.

Another noteworthy trend obtained in this study was that, in general, training did not influence overall judgments. Social judgment research has shown that initial judgments can be quite accurate (Ambady \& Rosenthal, 1992; Kenny, Horner, Kashy, \& $\mathrm{Chu}, 1992)$. However, it is unlikely that initial judgments would be accurate regarding deception. For the current study, with the exception of the deception ratings, there were 
no differences in ratings of honesty and likeability. Furthermore, regarding deception ratings, deception detection training participants rated deception higher than all other training groups. Thus, probe question participants indicated similar deception ratings to structured interview training participants even though probe training included deception detection training. Additionally, there were no differences in ratings of confidence and quickness in decisions. Based on these results, it seems that overall judgment is relatively independent of criteria application. This is important because it suggests that judgments may not be necessary for detecting deception. Rather, it may be possible to simply apply criteria to the statements and make decisions based on the outcome of the application.

From a theoretical standpoint, it appears that the criteria are working as intended. Bearing in mind that the answers were scripted, people were able to assess the statements and apply the criteria accordingly. Thus, individuals can be trained to use the criteria in an interview setting, providing preliminary construct validity evidence regarding the criteria. However, it is also the case that training beyond the criteria may suppress the ability to use the criteria checklist. Certainly, this topic requires further investigation.

A final noteworthy result regards the judgments and criteria application during the interview versus during the video. Having participants review the interview was done in an attempt to reduce cognitive load. This was especially important for participants forming probe questions. However, with the exception of number of criteria correct for deception detection participants, there were no differences in ratings or accuracy between the interview and video review. There are several implications of these findings. First, it may provide support for the suggestion that once people make social judgments they are unlikely to change them. Thus, while conducting a post-interview assessment is a good 
idea theoretically, it does not overcome initial judgment problems. These problems notwithstanding, it appears that the criteria were applied consistently over time. In general, the number of criteria checked and criteria accuracy were maintained across the evaluations. This may suggest that the checklist induced consistency on the part of the interviewer, which may provide a buffer for judgment problems.

To summarize, it appears that criteria training improves performance relative to no training. However, training beyond the criteria (e.g., probe training) reduces the ability to use the criteria checklist, but does not reduce accuracy in applying the criteria. This reduction in performance is likely due to cognitive load. Second, it appears that the criteria work from a practical and theoretical standpoint. That is, participants were able to apply the criteria during an interview and the criteria worked as intended. However, there may be a tendency to focus on deception, rather than truth, criteria. This tendency may be the result of the deception criteria being more concrete than the truth criteria. Third, in general, training did not influence the overall judgments, suggesting that judgments are relatively independent of criteria application. Finally, there were no differences between the interview and the video review in terms of judgments and criteria application. This suggests that, for better or worse, judgments remained stable. More importantly, criteria accuracy was maintained across the evaluations suggesting that the checklist induced consistency. 


\section{References}

Alliger, G. M., \& Janak, E. A. (1989). Kirkpatrick's levels of training criteria: Thirty years later. Personnel Psychology, 42, 331-342.

Ambady, N., \& Rosenthal, R. (1992). Thin slices of behavior as predictors of interpersonal consequences: A meta-analysis. Psychological Bulletin, 111, 256274.

Anastasi, A. (1982). Psychological Testing (5th ed.). New York, NY: Macmillan.

Barrick, M. R., \& Mount, M. K. (1991). The big five personality dimensions and job performance: A meta-analysis. Personnel Psychology, 44, 1-26.

Bowers, G. H. (1981). Mood and memory. American Psychologist, 36, 129-148.

Button, S. B., Mathieu, J. E., \& Zajac, D. M. (1996). Goal orientation in organizational research: A conceptual and empirical foundation. Organizational Behavior and Human Decision Processes, 67, 26-48.

Cacioppo, J. T., \& Petty, R. E. (1982). The need for cognition. Journal of Personality and Social Psychology, 42, 116-131.

Cacioppo, J. T., \& Petty, R. E. (1984). The need for cognition: Relationship to attitudinal processes. In R. P. McGlynn, J. E. Maddux, C. D. Stoltenberg \& J. H. Harvey (Eds.), Social perception in clinical and counseling psychology (pp. 91-119). Lubbock: Texas Tech University.

Cacioppo, J. T., Petty, R. E., Feinstein, J. A., \& Jarvis, W. B. G. (1996). Dispositional differences in cognitive motivation: The life and times of individuals varying in need for cognition. Psychological Bulletin, 119, 197-253.

Campion, M. A., Palmer, D. K., \& Campion, J. E. (1997). A review of structure in the selection interview. Personnel Psychology, 50, 655-701.

Clancy, W. J. (1999). Conceptual coordination: How the mind orders experience in time. Mahwah, NJ: Lawrence Erlbaum Associates.

Connelly, M. S., Mumford, M. D., Leritz, L. E., Ruark, G., Allen, M. T., \& Waples, E. P. (2003). Exploring Content Coding Procedures for Assessing Truth and Deception in Verbal Statements. Norman, OK: Final Technical Report for the Department of Defense Polygraph Institute.

DePaulo, B. M., Lindsay, J. J., Malone, B. E., Muhlenbruck, L., Charlton, K., \& Cooper, H. (2003). Cues to deception. Psychological Bulletin, 129, 74-118.

deTurck, M. A., \& Miller, G. R. (1990). Training observers to detect deception: Effects of self-monitoring and rehearsal. Human Communication Research, 16, 603-620.

Dodrill, C. B. (1983). Long term reliability of the Wonderlic Personnel Test. Journal of Consulting and Clinical Psychology, 51, 316-317.

Dodri11, C. B., \& Wamer, M. H. (1988). Further studies of the Wonderlic Personnel Test as a brief measure of intelligence. Journal of Consulting and Clinical Psychology, $56,145-147$.

Elaad, E. (2003). Effects of feedback on the overestimated capacity to detect lies and the underestimated ability to tell lies. Applied Cognitive Psychology, 17, 349-363.

Frank, M. G., \& Feeley, T. H. (2003). To catch a liar: Challenges for research in lie detection training. Applied Communication Research, 31, 58-75.

Freud, S. (1920/60). A general introduction to psychoanalysis (Joan Riviere, trans.). New York, NY: Washington Square Press. 
Friedman, H. S., \& Riggio, R. E. (1999). Individual differences in ability to encode complex affects. Personality and Individual Differences, 27, 181-194.

Gilbert, D. T., Pelham, B. W., \& Krull, D. S. (1988). On cognitive busyness: When person perceivers meet persons perceived. Journal of Personality and Social Psychology, 54, 733-740.

Goldberg, L. R. (1992). The development of markers for the Big-Five factor structure. Psychological Assessment, 4, 26-42.

Goldstein, I. L., \& Ford, J. K. (2002). Training in Organizations (4 ed.). Belmont, CA: Wadsworth.

Guion, R. M. (1990). Personnel assessment, selection, and placement. In M. D. Dunnette \& L. M. Hough (Eds.), Handbook of Industrial and Organizational Psychology (2 ed., Vol. 2, pp. 327-398). Palo Alto, CA: Consulting Psychologists Press.

Haccoun, R. R., \& Saks, A. M. (1998). Training in the 21 st century: Some lessons from the last one. Canadian Psychology, 39, 33-51.

Hilton, J. (1998). Interaction goals and person perception. In J. M. Darley \& J. Cooper (Eds.), Attribution and social interaction: The legacy of Edward E. Jones (pp. 127-197). Washington, D.C.: American Psychological Association.

Iacono, W. G., \& Patrick, C. J. (1997). Polygraph and integrity testing. In R. Rogers (Ed.), Clinical assessment of malingering and deception. (2nd ed., pp. 205-233). New York: Guilford Press.

Jackson, O. B. (2001). Developing and administering structured interviews. Oklahoma City, OK: State of Oklahoma Office of Personnel Management.

Jagacinski, C. M., \& Duda, J. L. (2001). A comparative analysis of contemporary achievement goal orientation measures. Educational and Psychological Measurement, 61, 1013-1039.

Johnson, M. K., \& Raye, C. L. (1981). Reality monitoring. Psychological Review, 88, 6785.

Kalbfleisch, P. J. (1994). The language of detecting deceit. Journal of Language and Social Psychology, 13, 469-496.

Kenny, D. A., Horner, C., Kashy, D. A., \& Chu, L. (1992). Consensus at zero acquaitance: Replication, behavioral cues, and stability. Journal of Personality and Social Psychology, 62, 88-97.

Kirkpatrick, D. L. (1987). Evaluation of training. In R. L. Craig (Ed.), Training and Development Handbook: A Guide to Human Resource Development (3 ed., pp. 301-319). New York, NY: McGraw-Hill.

Köhnken, G., Schimossek, E., Aschermann, E., \& Höfer, E. (1995). The cognitive interview and the assessment of the credibility of adults' statements. Journal of Applied Psychology, 6, 671-684.

Kraut, R. (1980). Humans as lie detectors. Joumal of Communication, 30, $209-216$.

Lancaster, J. S., \& Barsalou, L. W. (1997). Multiple organizations of events in memory. Memory, 5, 569-599.

Landry, K. L., \& Brigham, J. C. (1992). The effects of training in Criteria-based Content Analysis on the ability to detect deception in adults. Law and Human Behavior, $16,663-676$. 
Leippe, M. R., Manion, A. P., \& Romanczyk, A. (1992). Eyewinness persuasion: How and how well do fact finders judge the accuracy of adults' and children's memory reports? Journal of Personality and Social Psychology, 63, 181-197.

Levine, T. R., Park, H. S., \& McComack, S. A. (1999). Accuracy in detecting truths and lies: Documenting the "veracity effect". Communication Monographs, 66, 125144.

Lykken, D. T. (1979). The detection of deception. Psychological Bulletin, 86, 47-53.

Lykken, D. T. (1981). A tremor in the blood. New York, NY: McGraw Hill.

McComack, S. A. (1992). Information manipulation theory. Communication Monographs, 59, 1-16.

McCornack, S. A., \& Parks, M. R. (1986). Deception detection and relationship development: The other side of trust. In M. L. McLaughlin (Ed.), Communication Yearbook 9. Beverly Hills, CA: Sage.

McKelvie, S. J. (1989). The Wonderlic Personnel Test: Reliability and validity in an academic setting. Psychological Reports, 65, 161-162.

Miner, J. B., \& Capps, M. H. (1996). How honesty testing works. Westport, CT: Quorum Books.

Mumford, M. D., Schultz, R. A., \& Van Doorn, J. R. (2001). Performance in planning: Processes, requirements, and errors. Review of General Psychology, 5, 213-240.

Neuberg, S. L., \& Newsom, J. T. (1993). Personal need for structure: Individual differences in the desire for simpler structure. Journal of Personality and Social Psychology, 65, 113-131.

Ostroff, C. (1991). Training effectiveness measures and scoring schemes: A comparison. Personnel Psychology, 44, 353-374.

Porter, S., \& Yuille, J. C. (1996). The language of deceit: An investigation of the verbal clues to deception in the interrogation context. Law and Human Behavior, 20, 443-458.

Rabon, D. (1994). Investigative discourse analysis. Durham, NC: Carolina Academic Press.

Raskin, D. C., \& Podlesny, J. A. (1979). Truth and deception: A reply to Lykken. Psychological Bulletin, 86, 54-59.

Rosenthal, R., \& DePaulo, B. M. (1979). Sex differences in accommodation in nonverbal communication. In R. Rosenthal (Ed.), Skill in Nonverbal Communication. Cambridge, MA: Oelgeschlager, Gunn, \& Hain.

Ruby, C. L., \& Brigham, J. C. (1997). The usefulness of the Criteria-based Content Analysis technique in distinguishing between truthful and fabricated allegations: A critical review. Psychology, Public Policy, and Law, 4, 705-737.

Ruby, C. L., \& Brigham, J. C. (1998). Can Criteria-based Content Analysis distinguish between true and false statements of African-American speakers? Law and Human Behavior, 22, 369-388.

Sackett, P. R., Burris, L. R., \& Callahan, C. (1989). Integrity testing for personnel selection: An update. Personnel Psychology, 32, 221-245.

Sackett, P. R., \& Decker, P. J. (1979). Detection of deception in the employment context: A review and critical analysis. Personnel Psychology, 32, 487-506.

Sadowski, C. J., \& Gulgoz, S. (1992). Internal consistency and test-retest reliability of the Need for Cognition Scale. Perceptual and Motor Skills, 74, 610. 
Sapir, A. (1987). The LSI course on scientific content analysis (SCAN). Phoenix, AZ: Laboratory for Scientific Interrogation.

Saxe, L., Dougherty, D., \& Cross, T. (1985). The validity of polygraph testing: Scientific analysis and public controversy. American Psychologist, 40, 355-366.

Schank, R. C., \& Abelson, R. P. (1995). Knowledge and memory: The real story. In R. S. Wyer, Jr. (Ed.), Advances in social cognition (Vol. 8, pp. 1-85). Hillsdale, NJ: Lawrence Erlbaum Associates, Inc.

Schooler, J. W., Gerhard, D., \& Loftus, E. F. (1986). Qualities of the unreal. Journal of Experimental Psychology: Learning, Memory, and Cognition, 12, 171-181.

Semin, G. R., \& Feidler, K. (1988). The cognitive functions of linguistic categories in describing persons: Social cognition and language. Journal of Personality and Social Psychology, 54, 558-568.

Sporer, S. L. (1997). The less traveled road to truth: Verbal cues in deception detection in accounts of fabricated and self-experiences events. Applied Cognitive Psychology, 11, 373-397.

Steller, M., \& Köhnken, G. (1989). Criteria-based statement analysis. In D. C. Raskin (Ed.), Psychological methods in criminal investigation and evidence (pp. 217245). New York, NY: Springer.

Stevens, C. K., \& Kristof, A. L. (1995). Making the right impression: A field study of applicant impression management during job interviews. Journal of Applied Psychology, 80, 587-606.

Undeutsch, U. (1967). Evaluation of statement credibility. In U. Undeutsch (Ed.), Handbook of Psychology, Vol. 11: Forensic Psychology (pp. 26-181). Göttingen, Germany: Hogrefe.

Vrij, A., Edward, K., Roberts, K. P., \& Bull, R. (2000). Detecting deceit via analysis of verbal and nonverbal behavior. Journal of Nonverbal Behavior, 24, 239-263.

Wade, C., \& Tavris, C. (1998). Psychology. New York, NY: Longman.

Walters, S. B. (1996). Principles of kinesic interview and interrogation (CRC series in practical aspects of criminal and forensic investigations). Stamford, CT: CRC Press.

Weintraub, W. (1989). Verbal behavior in everyday life. New York, NY: Springer Publishing Company.

Wonderlic, C. F. (1992). Wonderlic Personnel Test Manual. Libertyville, IL: Wonderlic Personnel Test Inc.

Zickar, M. J., \& Ury, K. L. (2002). Developing an interpretation of item parameters for personality items: Content correlates of parameter estimates. Educational and Psychological Measurement, 62, 19-31. 


\title{
Appendix A
}

\author{
Informed Consent Form for \\ Research being conducted under the auspices of \\ The University or OKlahoma-Norman Campus
}

\section{INTRODUCTION}

This form documents an individual's consent for participating in a research project being conducted by faculty and graduate students in the Psychology Department at the University of Oklahoma-Norman Campus Title: Detecting Deception During a Structured Interview Principle Investigators: Lyle E. Leritz \& Michael D. Mumford, Department of Psychology

\section{DESCRIPTION OF THE STUDY}

The purpose of this research study is to examine the effectiveness of various methods for evaluating people's responses to questions in a hypothetical employment interview. Your role in this study is to participate in a structured employment interview, which will be videotaped, and to give us your reactions afterwards. There will be a short debriefing where you will find out more about the study and what we are hoping to learn, with an opportunity to ask questions. We will ask for a few more of your reactions at this time. The study will last 1 hour.

\section{POTENTIAL RISKS AND BENEFITS OF PARTICIPATION}

Risks: There are no anticipated risks to you as a result of your participation in this research. Benefits: You will receive research hours for your participation in and completion of this study. Additionally, you will be exposed to a structured interview and paper-and-pencil questionnaires similar to what you might experience in future employment and organizational contexts. This experience may eventually be helpful when applying for jobs or promotions.

\section{SUBJECT'S ASSURANCES}

Conditions of Participation: Participation in this research study is strictly voluntary. Refusal to participate will involve no penalty or loss of benefits to which you are otherwise entitled. You may discontinue participation at anytime with the understanding that you will receive experimental credit only for the amount of time you actually participated in the study.

Confidentiality: Your responses in this study will be completely confidential. Responses will carry only coded identification numbers to which your name, or other identifying information, will not be linked at any time. Data will be stored in secure research space designated for this project. Data for technical reports and papers resulting from this study will be presented in an aggregate or summary form. No individual identifiers will be collected.

Contacts for Questions about Research Subject's Rights: If you have questions about this research contact the Principal Investigator, Dr. Shane Connelly (405-325-4580). If you have questions about your rights as a research participant, please contact the Office of Research Administration at the University of Oklahoma (405-325-4757).

\section{SIGNATURE}

I have read and understand the Informed Consent and conditions of this project. I understand that questions can be directed to the investigators at any time and, at present, all of my questions have been answered. I hereby agree to participate in the above-described research. I understand my participation is voluntary and that I may withdraw at any time without penalty or loss of benefits to which I am otherwise entitled. I agree to abide by the rules of this project.

By checking this box, I agree to my participation to the interview video-taped. I understand that my name will not be linked to this tape and that the tape will be destroyed by August 1,2005 .

Signature

Date

Name (please print) 
Appendix B

\section{Structured Interview Training}

The purpose of the interview is to gather information about a job candidate. One advantage of interviews is that open-ended questions allow candidates to present more information than can be gathered from a job application alone. There are two basic types of interview used in employment settings: unstructured and structured. The unstructured interview is one with little or no advanced planning. The questions asked are left to the discretion of the interviewer. Different interviewers will ask different questions (based on personal taste) and are likely to reach different conclusions based on these questions. Therefore, unstructured interviews lack consistency for evaluating candidates resulting in interviewer bias. For example, in many unstructured interviews candidates are simply asked to describe themselves, resulting in a wide range of descriptions by different candidates. The interviewer can ask follow-up questions but is not required to do so.

Contrasting the unstructured interview is the structured interview. Structured interviews are characterized by the standardization of questions and procedures. The same questions are asked of all candidates. Furthermore the questions are asked in the same order for all candidates. Standardization reduces interviewer bias. Structured interviews are also characterized by the content of the questions asked. Questions should inquire about how candidates handled past situations that are similar to situations that could happen on the prospective job. Follow-up questions may be asked, however, they must be from a standardized list of follow-up questions. Yes/no questions should be avoided, as they do not allow candidates to display relevant knowledge and skills. Additionally, several topics are off limits in employment interviews. These include religion, race, marital status, parental status, national origin, age, disability, sex, political affiliation, and other personal information. Finally, interviewers should not deviate from the list of questions during the interview. This means that the interviewer should not engage in "small talk" with interviewees during the interview.

In addition to asking a predetermined set of ordered questions, interviewers should avoid influencing the interview with non-verbal behavior. For example, frowning informs the candidate that the interviewer may not agree with the response. As a result, candidates may become uncomfortable and their performance may be hindered or they might retract their answer changing it to a more satisfying response. In either case, the interviewer has unjustly influenced the interview. Laughing during the interview or lack of attention by the interviewer can have similar effects.

The following is a summary of the strengths of structured interviews.

Subjective and irrelevant questions are not asked, thus reducing interviewer bias

All candidates are asked same questions resulting in equal opportunity to display relevant job skills

$>$ Properly developed interviews have high reliability, meaning that different interviewers will have similar evaluations of a single candidate

Structured interviews are consistent with legal standards and are more legally defensible

$\checkmark$ Structured interviews increase the perception of fairness among candidates

Structured interviews make candidate dishonesty more difficult 


\section{Structured Interview Questions}

Structured interviews must be clearly job-related and should be written to reflect important dimensions of the job. There are four basic types of questions asked during structured interviews: job knowledge, past behavior, background, and situational.

Job knowledge questions ask interviewees to display specific job knowledge.

Example (Computer Engineer): "What are the differences between mainframe and desktop computers?"

Past behavior questions ask candidates to describe past training or job activities that relate to the prospective job.

Example (Airport Flight Controller): "This job requires remaining attentive over long time periods. Give some examples of when you have performed lengthy tasks that required continuous attention."

Background questions center on work experience, education, and other qualifications. Example (Salesperson): "Please sell me this product using basic selling techniques."

Situational questions present hypothetical situations that may occur on the job and require the candidate to describe how they would respond in such a situation.

Example (Project Coordinator): "Suppose a project you are working on is nearing the deadline and you have some important work to complete for the project. However, your supervisor kept requesting you to complete various unrelated tasks you feel are not your responsibility. What actions would you take in this situation?"'

Notice that all of the above questions are open-ended, allowing respondents to reveal more information about themselves than they would with yes/no questions. However, there are situations for which close-ended questions are appropriate, such as meeting a specific requirement (e.g. Do you have a driver's license?). 
There are several considerations that need to be taken into account when developing questions for the interview. Questions should not assist the candidate in responding. If you inform candidates that conscientiousness is required for the position and then ask if they are conscientious, the response is going to be the same for all candidates. Additionally, questions should minimize the amount of self-assessment on the part of the candidate. For example, candidates are unlikely to respond with negative information when asking, "How would you describe your social skill?"

Questions should be worded such that candidates understand what is being asked. Thus, the use of acronyms or unfamiliar terminology should be avoided. Also, questions should be to the point, making it easy for candidates to understand what is being asked.

The following is a summary of important characteristics of good interview questions.

$>$ Clearly job-related

$>$ Open-ended

$>$ Realistic

To the point and unambiguous

$>$ Written at language level of candidate

$>$ Not dependent upon skills to be learned on the job

$>$ Minimize amount of self-assessment 


\section{Knowledge Appraisal: Structured Interviews}

1. One characteristic that distinguishes structured interviews from unstructured interviews is:

1. Open ended questions

2. Consistency**

3. Follow-up questions

4. Evaluation

2. It is appropriate to ask candidates about sexual orientation.

1. True

2. False **

3. Which one of the following is NOT a strength of structured interviews?

1. Reduction in interviewer bias

2. Increased perception of faimess

3. Tailored to each candidate**

4. Legal defensibility

4. While candidates may reveal their opinions during an interview, it is generally inappropriate to ask questions directly concerning their opinion.

1. True**

2. False

5. Which of the following is NOT one of the four basic types of questions asked during a structured interview?

1. Job knowledge

2. Future behavior**

3. Background

4. Situational

6. The general purpose of an interview is to:

1. Gather information about a job candidate**

2. Evaluate job experience

3. Expose candidates to the work environment

4. Make legally defensible decisions

7. What do you want to AVOID when writing interview questions?

1. Open-ended questions

2. Job knowledge

3. Self-assessment**

4. Clarity

Note: ** denotes correct response. 
Now that you have been introduced to the basics of structured interviews, you will complete some exercises to apply the information you just learned. To begin, you will be presented with a target job with three job dimensions. Each dimension will have an example question. Following the examples, three new job dimensions are presented and your task is to write an interview question for each dimension. Remember, you should write questions that reflect the properties described above. For a quick review, questions should be open-ended, job related, and to the point. Questions should be written in one of the basic forms (job knowledge, past behavior, background, or situational).

Job knowledge questions ask interviewees to display specific job knowledge.

$>$ Past behavior questions ask candidates to describe past training or job activities that relate to the prospective job.

Background questions center on work experience, education, and other qualifications.

$>$ Situational questions present hypothetical situations that may occur on the job and require the candidate to describe how they would respond in such a situation.

Please continue to the next page to complete the exercises. 
Please look at the following example, which includes a target job with appropriate job dimensions and corresponding interview questions.

\section{Job: Secretary}

\begin{tabular}{l|l} 
Dimension & \multicolumn{1}{|c}{ Question } \\
\hline 1. Decision Making & $\begin{array}{l}\text { 1. Suppose a client needs some information from your supervisor's personal files } \\
\text { which you know is essential for the business transaction. However, your } \\
\text { supervisor is out of town and cannot be reached and you have neither been } \\
\text { permitted nor forbidden from accessing these files. What actions would you } \\
\text { take in this situation? }\end{array}$ \\
\hline 2. Multitasking & $\begin{array}{l}\text { 2. Describe a past situation that required you to complete multiple tasks } \\
\text { simultaneously and how you handled the situation. }\end{array}$ \\
\hline 3. Customer & $\begin{array}{l}\text { 3. Suppose a two existing clients came to you in need of immediate service. } \\
\text { However, the person responsible for providing this service is currently busy. } \\
\text { Both of these clients have been loyal customers for several years. What actions } \\
\text { would you take in this situation? }\end{array}$
\end{tabular}

After reviewing the above example, write one interview question that addresses each dimension. You may use any of the 4 types of interview questions (job knowledge, past behavior, background, or situational).

\section{Job: Secretary}

\begin{tabular}{l|l} 
Dimension & Question \\
\hline 1. Record Keeping & 1. \\
\hline 2. Responsibility & 2.
\end{tabular}

Please continue to the next page for the next exercise. 
Please look at the following example, which includes a target job with appropriate job dimensions and corresponding interview questions.

\section{Job: High School Teacher}

\begin{tabular}{l|l} 
Dimension & \multicolumn{1}{|c|}{ Question } \\
\hline 1. Communication & $\begin{array}{l}\text { 1. Describe some past situations that required you to communicate to } \\
\text { a large audience. }\end{array}$ \\
\hline $\begin{array}{l}\text { 2. Handling } \\
\text { Conflict }\end{array}$ & $\begin{array}{l}\text { 2. Several students are disturbing a fellow student during class causing the } \\
\text { student to withdraw from classroom exercises and discussion. Describe } \\
\text { how you would handle this situation regarding the disturbing students as } \\
\text { well as the student being disturbed. }\end{array}$ \\
\hline $\begin{array}{l}\text { 3. Continuing } \\
\text { Education }\end{array}$ & $\begin{array}{l}\text { 3. Describe how you plan to further your training and keep up-to-date on } \\
\text { the latest research and teaching techniques. }\end{array}$
\end{tabular}

After reviewing the above example, write one interview question that addresses each dimension. You may use any of the 4 types of interview questions (job knowledge, past behavior, background, or situational).

\section{Job: High School Teacher}

\begin{tabular}{l|l} 
Dimension & Question \\
\hline 1. Advising & 1. \\
\hline $\begin{array}{c}\text { 2. Creative } \\
\text { Thinking }\end{array}$ & 2.
\end{tabular}

Please continue to the next page for the next exercise. 
Please look at the following example, which includes a target job with appropriate job dimensions and corresponding interview questions.

\section{Job: Flight Attendant}

\begin{tabular}{l|l} 
Dimension & Question \\
\hline $\begin{array}{c}\text { 1. Problem } \\
\text { Solving }\end{array}$ & 1. Discuss a complex problem you have had to solve in the past. \\
\hline 2. First Aid & $\begin{array}{l}\text { 2. Suppose a passenger is complaining of chest pain and nausea. What do } \\
\text { these symptoms indicate and what actions do you need to take? }\end{array}$ \\
\hline $\begin{array}{l}\text { 3. Social } \\
\text { Awareness }\end{array}$ & $\begin{array}{l}\text { 3. Describe a past situation that required you to maintain awareness of the } \\
\text { needs of the people around you while you conducted your work. }\end{array}$
\end{tabular}

After reviewing the above example, write one interview question that addresses each dimension. You may use any of the 4 types of interview questions (job knowledge, past behavior, background, or situational).

\section{Job: Flight Attendant}

\begin{tabular}{l|l} 
Dimension & Question \\
\hline 1. Communication & 1. \\
\hline $\begin{array}{c}\text { 2. Handling } \\
\text { Stress }\end{array}$ & 2
\end{tabular}

Please continue to the next page for the next exercise. 
Please look at the following example, which includes a target job with appropriate job dimensions and corresponding interview questions.

\section{Job: Waiter or Waitress}

\begin{tabular}{l|l} 
Dimension & Question \\
\hline 1. Maintenance & $\begin{array}{l}\text { 1. Discuss how you have performed tedious or non-essential activities } \\
\text { during work. }\end{array}$ \\
\hline $\begin{array}{l}\text { 2. Handling } \\
\text { Stress }\end{array}$ & $\begin{array}{l}\text { 2. Describe some past situations that required you to complete multiple } \\
\text { tasks simultaneously. }\end{array}$ \\
\hline 3. Teamwork & $\begin{array}{l}\text { 3. Describe a past situation requiring teamwork such that successful } \\
\text { completion of your work was dependent on the work of your coworkers. }\end{array}$
\end{tabular}

After reviewing the above example, write one interview question that addresses each dimension. You may use any of the 4 types of interview questions (job knowledge, past behavior, background, or situational).

\section{Job: Waiter or Waitress}

\begin{tabular}{l|l} 
Dimension & Question \\
\hline $\begin{array}{c}\text { 1. Social } \\
\text { Awareness }\end{array}$ & 1 \\
\hline $\begin{array}{c}\text { 2. Customer } \\
\text { Relations }\end{array}$ & 2.
\end{tabular}

You are now completed with structured interview training. Please turn to the next page for further instructions. 
Appendix C

\section{Deception Detection Traiming}

As previously mentioned, structured interviews make it more difficult for job candidates to provide inaccurate or false information. This is important because research has shown that as many as $50 \%$ of job candidates provide significantly inaccurate information during a job interview. The importance of using structured interviews should be even more apparent. However, even though structured interviews make it more difficult for candidates to lie during an interview, they can, nevertheless, still provide false information. Furthermore, using a structured interview alone will not help an interviewer determine the authenticity of the candidate's statements.

With these limitations in mind we have developed criteria that can be applied to each candidate's statements in an effort to detect deception. There are two basic types of criteria: Truth Criteria and Deception Criteria. Truth criteria are designed to detect truth in statements such that the presence of the criteria indicates truth. Conversely, deception criteria are designed to detect deception in statements such that their presence indicates deception. It is important to note that presence of one or two deception criteria (or truth criteria) in a candidate's statements does not necessarily indicate deception (or truth). Rather, you must take into account the combination of truth and deception criteria. There are no established guidelines for deciding if a respondent is honest or not (e.g. more than four deception criteria means the respondent is lying). In making your judgments, you must consider the ratio of truth to deception criteria rather than counting criteria.

To help you better understand the criteria and how to apply them, you will be given the list of criteria with accompanying definitions. Knowing the definitions of the criteria should help you understand why each is a truth or deception criterion and how it may appear in a statement. Additionally, there is an example statement that demonstrates how each criterion may appear in a statement. It is important to keep in mind that these are only examples and the appearance of the criteria may appear in different forms. Furthermore, a statement may contain more than one of the criteria. For simplicity, the examples are intended to reflect only the criteria they are presented with (though some are related enough that you may see additional criteria in some examples). On the following pages the criteria are presented along with definitions and examples. Following this you are required to answer several questions regarding the criteria. 


\section{Deception Criteria}

1) Reasons for evaluation of others NOT provided (AT)

Definition: Present when respondent mentions the evaluation of another person but does not provide a reason for that evaluation.

Rational: When people discuss their evaluations of other people they will typically include reasons for this evaluation, especially if the evaluation is unfavorable. Not providing a reason for the evaluation might indicate deception.

Example: "A project I was working on turned out very poorly because my partner was a terrible worker. We ended up having to start over and I requested a new partner."

2) Speaks in second person tense (AU)

Definition: Present when respondent's statements have relatively few self-references such as "I". Most often seen in the form of "you" statements.

Rational: When people are deceptive they sometimes try to disconnect themselves from the lie by not using self-references such as I or me when discussing events they were supposedly involved in.

Example: "Being a manager is hard work. You have to be in charge of what people are doing and where they need to be. You are responsible for the performance of your group. You also have to solve other people's problems."

\section{3) No explanation of stereotypically "odd" behaviors (CV)}

Definition: Present when a respondent describes behaviors typically viewed as odd but does not give an explanation for the behaviors.

Rational: When people describe behaviors that might be viewed as odd by others they will typically want to provide an explanation for that behavior. When someone is being deceptive they may not provide an explanation for such behaviors because they do not actually perform them, thus they do not feel the need to explain.

Example: "When I am alone in my office I like to hang my pants up and wear shorts."

\section{Please review the above criteria a second time before moving on to the next set of criteria.}




\section{Deception Criteria (continued)}

4) Lacks concrete descriptions (DF)

Definition: Present when respondent vaguely describes situations or behaviors.

Rational: When being deceptive, it is difficult for people to give concrete descriptions of events or situations they were supposedly involved in.

Example: "I have worked on many projects in the past. They usually turned out pretty well. Although I have worked on some difficult projects as well."

\section{5) Does not discuss past behavior (AT)}

Definition: Present when the respondent discusses many issues relevant to the topic such as their opinion but does not mention any specific behaviors or actions.

Rational: When asked questions regarding past behavior, a deceptive person will have difficulty describing behaviors that they did not engage in. As a result, they will answer the question by describing something other than behavior, such as an opinion. Example: "I usually do my best when I am in charge of completing a project because I take pride in my work and my ability to get the job done. I also like to work under pressure because that is when I do my best work"

6) Boasting/Bragging (DF)

Definition: Present when respondent is bragging (such as listing many achievements).

Rational: When people are deceptive they often feel the need to emphasize certain aspects of their accomplishments, basically overcompensating for their deficiencies. This often appears to listeners as boasting or bragging.

Example: "I have been responsible for many employees. In my last three jobs I was responsible for 12 employees, 23 employees, and 17 employees. They always liked working for me."

Please review the above criteria a second time before moving on to the next set of criteria. 


\section{Deception Criteria (continued)}

7) Lack of emotion for emotional event (EM)

Definition: Present when respondent is discussing an arousing event but does not display any emotion or indicate the experience of emotion.

Rational: When people describe emotional events they experienced they often express

similar emotions in their descriptions. When someone is describing emotional events they did not experience (thus being deceptive) they typically will not display expected emotions.

Example: "Our company was experiencing major financial trouble and they were letting many employees go. Several of the people in my department had been laid-off the previous month and they announced there would be more lay-offs in my department soon. At the end of the next week I received my release papers so I had to find a new job. I was unemployed for six months because there were no jobs available."

8) Emphasizes own contributions to successful events (AT)

Definition: Present when the respondent focuses mainly on their contribution to the success of group tasks.

Rational: When describing past successes, deceptive people will emphasize their own contributions to the success. This is another situation where the person is overcompensating or disguising some deficiency.

Example: "The project my team was working on was a big success. I was so happy because I did all of the work for the final presentation which is what really sold it to management."

Please review the above criteria a second time before moving on to the next set of criteria. 


\section{Truth Criteria}

1) Discusses goals or outcomes (AU)

Definition: Present when a respondent mentions some objective or the eventual outcome in achieving or not achieving a goal.

Rational: Goals are abstract criteria for personal accomplishment. Thus, they are unlikely to be mentioned by someone who is not telling the truth.

Example: "We had a few difficult customers that came in frequently. They were usually tough to deal with but we attempt to satisfy all customers. I typically did not have to deal with any of them but when I did I tried my best to make them happy."

2) Dissatisfying or less than optimal outcome noted (AU)

Definition: Present when a respondent mentions some result that was disappointing.

Rational: People want to present themselves as best they can. When someone is being deceptive, it is unlikely they will mention anything that might make them look less than ideal. Thus, when someone mentions a dissatisfying outcome they are likely being honest.

Example: "The first project that I was in charge of was very difficult. I had a pretty good team but my organization skills were still developing. I spent many weekends making up for time that was lost because of my direction. The whole project was a disaster, but I learned from it and went on."

\section{3) Mentions unusual/distinct details (AU)}

Definition: Present when the respondent's statement includes out of the ordinary elements.

Rational: When people are involved in events it is common for them to observe some unusual incidents that they may subsequently describe.

Example: "When I was working as a vet assistant we had to be careful when we worked with the animals. One time I was assisting on a surgery and another dog got loose and was running through the office. It came flying through the room we were in and knocked over the tray of tools. It was kind of comical, we caught the dog and then had to clean up and finish the surgery."

Please review the above criteria a second time before moving on to the next set of criteria. 


\section{Truth Criteria (continued)}

4) Discusses blockages to goal attaimment $(\mathrm{CV})$

Definition: Present when respondent discusses factors interfering with reaching a goal.

Rational: When someone is trying to accomplish a goal they will likely experience events that interfere with goal attainment. As a result, they may mention these blockages.

Example: "I was collecting money for a charity drive one summer and it was the final day for receiving funds from the donors. I was having trouble contacting a few donors, they were not returning any of my calls. So, I had to find them in person to collect the money. It took me all day to locate three people to collect their donations."

\section{5) Mentions alternatives that were not used (CV)}

Definition: Present when respondent discusses or implies options available but not used for completing a task.

Rational: When people are involved in making decisions they face one or more alternatives. In some cases the alternative may have been the better choice. If someone is fabricating their statements they did not choose between alternatives and are less likely to mention them.

Example: "When I first started at my last job I had to make a decision regarding an equipment change. Since I was new and I didn't know much about the existing problem with the equipment it was a tough choice. At first I almost chose some equipment with similar problems but one of my coworkers helped me out and we fixed the problem."

\section{6) Discusses lessons learned (CV)}

Definition: Present when respondent mentions what they gained from a situation (e.g. a moral to the story).

Rational: People often gain something from their experiences. As a result, they will often mention what they have learned from these various experiences.

Example: "We lost some important documents at work and I was the last person to check them out. I knew I had turned them in but I could not prove it. We found them a couple weeks later. Apparently somebody filed them in the wrong drawer. From then on I always asked for a receipt when I retumed documents."

Please review the above criteria a second time before moving on to the next set of criteria. 


\section{Truth Criteria (continued)}

7) Discusses emotions of key participants (EN)

Definition: Present when respondent talks about the feelings or emotions of others they are involved with.

Rational: When people interact they observe the emotions of other people. The emotions of other people are more prominent for certain events, such as conflict. When describing interactions with others, people are likely to mention the emotions other people displayed.

Example: "When our secretary quit it was really hard for my boss. She had worked for him for many years and he trusted her. He was upset for quite some time."

8) Mentions conflict with powerful others (AT)

Definition: Present when the respondent talks about a conflict or disagreement they had with someone of power (e.g. supervisor or parent).

Rational: It is common for people to experience conflict either at home or at work. It might be viewed as unfavorable to mention having a conflict with one's boss. As a result, deceptive people are unlikely to mention conflict with a superior.

Example: "My boss wanted me to check the files for inconsistencies in billing but I had already checked them. We got into a heated argument about the efficiency of checking them again when there were other possibilities for the errors."

The next exercise requires you to answer some multiple choice questions regarding deception detection. Please use the answer sheet to indicate you answers.

Please review the above criteria a second time before moving on to the next exercise. 


\section{Knowledge Appraisal: Deception Detection}

1. Statements with relatively few self-references are indicative of which criterion?

1. Mentions conflict with powerful others

2. Speaks in second person tense**

3. Boasting/Bragging

4. Lacks concrete descriptions

2. Which of the following is a deception criterion:

1. Discusses lessons learned

2. Mentions unusual/distinct details

3. Does not discuss past behavior**

4. Discusses emotions of key participants

3. Which of the following is a truth criterion:

1. Discusses blockages to goal attainment**

2. Emphasizes own contributions to successful events

3. Speaks in second person tense

4. Reasons for evaluation of others NOT provided

4. Discussion of issues relevant to the topic with little mention of specific behaviors or actions is indicative of which criterion?

1. Discusses emotions of key participants

2. Mentions alternatives that were not used

3. Mentions unusual/distinct details

4. Does not discuss past behavior**

5. The presence of even one deception criterion means the respondent is probably lying.

1. True

2. False**

6. As many as of job candidates provide significantly inaccurate information during a job interview.

1. $10 \%$

2. $25 \%$

3. $50 \% * *$

4. $75 \%$

Note: ** denotes correct response. 
Now that you have been introduced to the criteria and what they mean, you will complete some exercises to practice applying the criteria. To begin, you will be presented with statements that contain one or more criteria along with a list of potential criteria. Also included is the interview question leading to each statement. Your task is to read the statement and identify which criteria are present. Please note each statement may contain as few as one and as many as three criteria.

\section{Exercise 1}

Question: Describe a time when you had to deal with a difficult coworker or customer on a job.

Statement: "When I was working as a salesclerk I hated working with this one guy in particular. Whenever I had to work with him I would do everything I could to stay away. I would try to find other tasks to work on so I could be alone or with other people."

\section{Criteria:}

1. Reasons for evaluation of others NOT provided

2. Discusses goals or outcomes

3. Discusses lessons learned

4. Does not discuss past behavior

\section{Exercise 2}

Question: Describe a time when a travel experience did not go according to your plan.

Statement: "When I was in New York I was traveling by train and one night the local union went on strike so the trains stopped running. Rather than take a taxi I ended up staying at the train station for the night. I started sleeping in a field near the station. In the middle of the night I had to get out of the field and I ended up sleeping on a cardboard box in the parking lot.".

\section{Criteria:}

1. No explanation of stereotypically "odd" behaviors

2. Discusses blockages to goal attainment

3. Discusses emotions of key participants

4. Mentions alternatives that were not used

The next page contains the answers to these exercises. Please compare your answers with the key. Please do NOT change your answers on the answer sheet after reading the answer key. 


\section{Answer: Exercise 1}

The criteria present in this statement are 1 and 4 .

The respondent indicates a dislike for a coworker, which is an evaluation. However, the reason for disliking the coworker is not mentioned, thus, the criterion "Reasons for evaluation of others NOT provided" is present.

Also, the respondent does not really discuss any behaviors. Thus, the criterion "Does not discuss past behavior" is present.

Note, the respondent does not discuss goals or outcomes or lessons learned. Thus, the criteria "Discusses goals or outcomes" and "Discusses lessons learned" are not present.

\section{Answer: Exercise 2}

The criteria present in this statement are 1,2, and 4.

The respondent discusses sleeping in a field and then on a cardboard box. This is an "odd" behavior that might have an explanation (such as no money for a hotel). However, the respondent does not indicate a reason for engaging in this behavior. Thus, the criterion "No explanation of stereotypically "odd" behaviors" is present.

The respondent discusses traveling and encountering trouble reaching some destination due to the train stoppage. Thus, the criterion "Discusses blockages to goal attainment" is present.

Finally, the respondent indicates staying the night rather than take a taxi. Thus, the criterion "Mentions alternatives that were not used" is present.

Note, the statement does not include any mention of other people, thus, the criterion "Discusses emotions of key participants" is not present.

When you have finished comparing your answers to the key and understand why each criterion is present or nor present please continue to the next page to continue with the remaining exercises. 


\section{Exercise 3}

Question: Describe a situation that required you to complete multiple tasks simultaneously.

Statement: "Most of the things you do in life require you to complete multiple things at the same time. It isn't always easy to do that though. Sometimes you have a project that you are working on and there are too many things to do at the same time so you have to get somebody to help you. I have worked in a group situation and that made it a little easier as long as you get along with everybody. I got into a bunch of arguments with my boss. last year about how to do my job. That makes it more difficult, when you spend half the time arguing and not getting any work done."

\section{Criteria:}

1. Speaks in second person tense

2. Boasting/Bragging

3. Lacks concrete descriptions

4. Mentions conflict with powerful others

\section{Cxercise 4}

Question: Describe a project that you had to complete with little or no direction.

Statement: "When I was a senior in high school we had to complete a final project to graduate. There were no specific directions for the project so I decided to examine the role of traditional farmily values in athletics. I was hoping that I could demonstrate that successful student-athletes came from more traditional homes. It turned out that getting data for what I wanted was much more difficult that I anticipated. I ended up changing the project to look at whether grades dropped during the athletic season versus the offseason. I was not happy with changing that because I think I had a more valuable idea to begin with but the project passed and I graduated.

\section{Criteria:}

1. Discusses goals or outcomes

2. Discusses lessons learned

3. Dissatisfying or less than optimal outcome noted

4. Mentions unusual/distinct details

The next page contains the answers to these exercises. Please compare your answers with the key. Please do NOT change your answers on the answer sheet after reading the answer key. 


\section{Answer: Exercise 3}

The criteria present in this statement are 1,3, and 4.

In the first half and final part of the statement the respondent speaks with the general term "you" rather than use "1" or "me". These parts of the statement are spoken in the second person tense. Thus, the criterion "Speaks in second person tense" is present.

The respondent never gives any descriptions of the events or actions surrounding the events, thus, "Lacks concrete descriptions" is present.

The respondent does mention engaging in arguments with a supervisor, thus, "Mentions conflict with powerful others" is present.

There is no indication that the respondent is "Boasting or bragging".

\section{Answer: Exercise 4}

The criteria present in this statement are 1 and 3.

The respondent discusses the requirement of completing a project in order to graduate (a goal) as well as the outcome of the attempts to complete the task. Thus, "Discusses goals or outcomes" is present.

The respondent discusses failing in the first attempt to complete the project, thus, "Dissatisfying or less than optimal outcome noted" is present.

The respondent never mentions what lessons were learned from the experience (even though there was undoubtedly some lesson learned). Thus, "Discusses lessons learned" is not present.

Nothing in the statement can be regarded as unusual or distinct, thus, "Mentions unusual/distinct details" is not present. An example of an unusual or distinct detail might have been that the respondent indicated they collected information from a professional sports team.

When you have finished comparing your answers to the key and understand why each criterion is present or nor present please continue to the next page to begin a new exercise. 
On the following pages you will be presented with example statements. Your task is to read each statement and indicate which criteria are present. This task is similar to the task you just completed with the exception that it is not multiple-choice. Rather, you are required to decide which criteria are present from the entire list of criteria.

Here is a list of the criteria in alphabetical order. Please use this list when identifying criteria present in the statements on the following pages. Note, you will circle the criterion number rather than write the criterion itself. Please note each statement may contain as few as one and as many as three criteria. An answer key follows each exercise set.

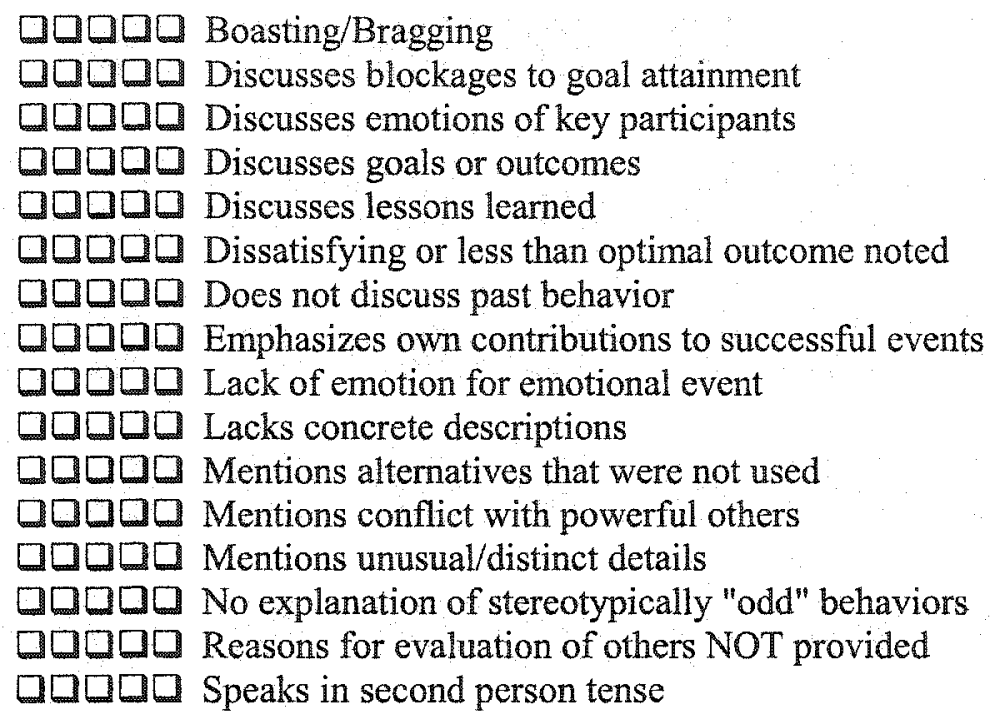


Please read through the following statements and indicate which criteria are present in each statement.

Question 1: Describe a work project that you had to complete with little or no direction.

Statement: "I had a job where I worked with a group. We each had our own responsibilities, and basically worked alone. The first project I worked on was difficult. I had to go through all the databases and look for errors. The first time I did it was not good. I went through each database and replaced all of the numbers that indicated missing data, which is a problem because the program was set up to recognize those characters. I reported my progress and my supervisor told me I had done it wrong. She was very upset at first but calmed down, probably because it was my first time. One of my coworkers showed me what to do so now I know what not to do."

Criteria:

Question2: Tell me about a specific problem you had to solve in a social or work setting.

Statement: "Whenever you are doing your job and you see a coworker not doing what they are supposed to do, there is nothing that you can really do about it, cause you don't want to go and rat on them or tell on them, so you have to cover for them and do what they were supposed to do, which is not fair, because you are covering for yourself and somebody else."

Criteria:

Question3: Discuss a complex problem you have had to solve in the past.

Statement: "One time our car broke down and we didn't know what the problem was. I knew a little about cars so I took a look. At first I couldn't figure it out. Then I remembered when my dad's car broke. The distributor was messed up and I needed a screwdriver to get it off. I took it off with a wrench and my bare hands which is pretty cool. Then I got creative and cleaned it out with some leaves which is pretty ingenious. It ended up working, I got the car fixed by myself.

Criteria: 
The following contains the answers to the preceding exercises. Please note, you may have seen criteria in the statements that are not included in the answer key. This does not mean they were not present. Rather, these answers represent the strongest criteria present in the statements (and most justifiable based on the statements). However, if you did not correctly identify any criteria you may need to re-examine the definitions before moving on.

The correct criteria for the preceding exercises are as follows:

Questionl:

Discusses emotions of key participants $(\sharp 3)$

Discusses lessons learned (\#5)

Dissatisfying or less than optimal outcome noted (\#6)

Question 2:

Does not discuss past behavior (\#7)

Lacks concrete descriptions (\#10)

Speaks in second person tense (\#16)

Question3:

Boasting/Bragging ( $\# 1$ )

Discusses blockages to goal attainment (\#2)

Emphasizes own contributions to successful events (\#8)

Please make sure you understand why each criterion is present in the statements before moving on to the next section. 
Please read through the following statements and indicate which criteria are present in each statement.

Question4: Describe a time when you recently had to deal with a difficult coworker or customer on a past or current job.

Statement: "I had a job where I always argued with my boss. We never agreed on anything. I don't think he was the brightest guy around. One time we got into an argument about how to inventory new shipments. He wanted to go through each item and check it off and I thought it would be quicker to use the list they gave us since we never had anything missing anyway."

Criteria:

Question5: Discuss problems you have encountered while traveling and how you handled them.

Statement: "Once I was driving to Atlanta for a job and I lost the directions. I knew how to get to Atlanta but once I was there I didn't know where to go. I was hoping to get there early so I could tour around town. I couldn't call anyone since the contact info was on the directions. When I got there I thought about getting online and finding directions but didn't think that would work. I ended up finding the place on accident when I was looking for somewhere to eat so I was able to tour around town."

Criteria:

Question6: Discuss a social or family problem you have had to solve in the past.

Statement: "When my grandfather died I was in charge of organizing the wake. I was not pleased about that because I had other things to do. I was trying to get my truck running and wanted to keep working on that. My mother had all these things she wanted to do for the wake. She wanted to have certain music played and these special decorations. There was supposed to be a variety of food like sushi, little smokies, mozzarella sticks and stuff. I ended up helping but got out of being in charge of organizing it."

Criteria:

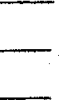


The following contains the answers to the preceding exercises. Please note, you may have seen criteria in the statements that are not included in the answer key. This does not mean they were not present. Rather, these answers represent the strongest criteria present in the statements (and most justifiable based on the statements). However, if you did not correctly identify any criteria you may need to re-examine the definitions before moving on.

The correct criteria for the preceding exercises are as follows:

Question 4:

Mentions conflict with powerful others (\#12)

Reasons for evaluation of others NOT provided (\#15)

Question 5:

Discusses blockages to goal attainment ( $\# 2$ )

Discusses goals or outcomes (\#4)

Mentions alternatives that were not used (\#11)

Question 6:

Lack of emotion for emotional event ( $\# 9)$

Mentions unusual/distinct details (\#13)

No explanation of stereotypically "odd" behaviors (\#14)

Please make sure you understand why each criterion is present in the statements. If you are comfortable with the criteria continue to the next page. Otherwise, please review the criteria.

You are now completed with deception detection training. Please turn to the next page for further instructions. 
Appendix D

\section{Probe Question Training}

Structured interviews may vary in several ways. One common variation of structured interviews involves the use of follow-up or probe questions. The purpose of probe questions is to allow an interviewer to extract additional information from an interviewee. Typically, probe questions are asked after an interviewee has had a chance to respond to the initial question. Probe questions have the advantage of allowing an interviewee to communicate information beyond what was originally stated. Additionally, probe questions allow an interviewer to gain more information about a candidate in order to make decisions. Asking probe questions makes it more difficult for an interviewee to "gloss over" certain aspects of the original questions. As a result, probe questions are useful for detecting deception because they allow an interviewer to gather additional information in order to identify additional criteria for detecting deception.

To maintain the structured interview format interviewers are provided with a list of available probe questions to ask rather than allowing them to generate their own probe questions. Furthermore, probe questions should be direct and job relevant. Typically, probe questions are formulated based on global content. Probe questions should focus on the context of the response, the interviewee's response to the situation, and the outcome of the situation. For example, a context probe question might ask, "What were the circumstances surrounding this situation?", while a response probe question might ask, "What did you do in this situation?". Finally, a outcome probe question might ask, "How did things turn out?". Probe questions such as these should only be asked when the respondent does not address these aspects in their answer.

There are several potential strategies for using probe questions. In traditional interrogation type interviews, the interviewer confronts the respondent with information that may contradict earlier statements. Typically, this information comes from earlier statements. The goal here is basically to elicit an admission of deceit from the respondent. However, this approach can elicit false confessions and is very uncomfortable for the respondent. As a result, it is not conducive to conducting employment interviews.

An alternative approach concedes that most people are not entirely truthful in all of their statements. As a result, both honest and dishonest people are lying somewhat. The difference between the two is in the degree to which their statements contain truth. Truthful statements are mostly true while deceptive statements are mostly not true. With these limitations in mind, it is useful to understand that when people relay information they are basically telling a story. Consequently, there are several strategies that can be employed to better ascertain if people are being honest. The strategies available are as follows: Additional Information, Inconsistency, Expansion, and Interference.

The purpose of the Additional Information strategy is simply to obtain further information from respondents in order to identify additional truth and deception criteria. For example, after the initial response, the interviewer might say, "Tell me more about that situation" or "How did things turn out?" Asking these types of general questions requires the respondent to give additional information. However, one drawback of this approach is that if allowed to speak too long, it is likely that most, if not all, criteria will be present in some of the statements. Thus, the interviewer must be cautious not to elicit too much information. 
The Inconsistency strategy requires asking probe questions that are inconsistent with the response (basically asking questions that "mess up" the story). Another way to think about this strategy is that the interviewer is asking questions that are inconsistent with the statement but might normally occur. For example, the interviewer might say, "Most of the time resolving conflict between friends is emotionally draining, why were you able to do it with such ease"? This strategy is very useful when used effectively. However, it is more difficult to use than the other strategies because it requires an interviewer to understand what typically happens in a given situation and subsequently communicate that to the respondent.

In the Expansion strategy respondents are allowed to expand their stories as much as possible, resulting in an increase in self-presentation. This approach is similar to the first strategy in allowing respondents to increase the content of their stories. However, it differs in that probe questions are not specific to the response. For example, the interviewer might say, "Please tell me more". This type of question does not direct the respondent towards any specific aspect of the response. Rather they are encouraged to expand the response in general. As with the first strategy, this approach may result in too much information.

The Interference strategy is slightly more complex. When people are deceptive, they have certain details activated in memory (i.e., the details surrounding their deception). This approach is most easily applied when the statement is full of details. Probe questions that are unrelated to the response are asked in an attempt to disrupt the flow of the response. For example, assuming the respondent had been discussing work habits, the interviewer might ask, "Tell me how have you handled conflicts between family members at home". This sudden change should interfere with the details activated in memory. Subsequently, the interviewer should ask an additional probe question specific to the original response. As a result of the interference, a deceptive respondent should have more trouble reconstructing the original information. Note, this approach is easily combined with the first strategy.

Each of the above strategies is an effective method for identifying additional truth and deception criteria. However, each have strengths and weaknesses that must be considered when deciding which to use. The responses given during the interview can dictate which strategy is appropriate to use. For example, if a statement regarding a situation includes typical reactions from those involved the inconsistency approach will not work well.

It is important to note that it is not always necessary to ask a probe question. It is common for a statement to contain enough information such that asking a probe question will be of little value. As a result, a fifth strategy to asking probe questions is to not ask a probe question. 


\section{Thowledge Appraisal: Probe Questions}

1. What is the general purpose of probe questions?

1. To force the respondent to mess up

2. To obtain additional information**

3. To clarify what the respondent said

4. To mislead the respondent

2. How are probe questions typically formulated during the interview?

1. From a list of available probe questions**

2. Whatever the interviewer feels like asking

3. Randomly from a list

4. Probe questions should be avoided whenever possible

3. Which probe strategy requires an interviewer to understand what typically happens in a given situation?

1. Additional Information

2. Inconsistency**

3. Expansion

4. Interference

4. Why are probe questions effective for detecting deception?

1. They make a respondent uncomfortable

2. They make interviews longer

3. They do not allow a respondent to gloss over details**

4. Probe questions are not effective for detecting deception

5. Which two strategies might result in too much information?

1. Inconsistency \& Interference

2. Inconsistency \& Expansion

3. Additional Information \& Interference

4. Additional Information \& Expansion**

6. What does interference hinder?

1. Decisions

2. Basic knowledge

3. Details activated in memory**

4. Monitoring

7. It is NOT necessary to always ask a probe question.

1. True T* $^{*}$

2. False

Note: ** denotes correct response. 
The following list contains probe questions typically asked during an interview. Additionally, the questions are written such that you can adapt them to the statements. Some statements contain multiple options for tailoring them to the response. These are indicated with an underline where you can insert the appropriate comment (with examples in parentheses). Some examples are stated in general terms (e.g. someone's reaction) such that you need to make them specific to the statement (e.g. how your boss reacted). Please review these probe questions and move on to the next exercise.

\section{Additional Information}

1. Describe how things tumed out regarding

2. Tell me more about (the situation, someone's reaction, etc.).

3. What were the circumstances surrounding (the situation)?

4. What did you do (regarding the situation)?

\section{Inconsistency}

1. Most of the time (some activity) is (difficult, not normal, performed by professionals, etc.) why were you (able to, asked to) complete it?

2. Typically (some event or reaction happens). Why did this not happen to you?

3. In most situations similar to yours situation different? (some event or reaction occurs). Why was your

4. It is not normal for (event or reaction to occur). Why did it happen in your situation?

\section{Expansion}

1. Please tell me more about

2. Could you give me some examples of

3. I find interesting. Could you tell me more information about that?

4. You mentioned but you did not describe it much. Would you please tell me more about (same as previous blank).

\section{Interference}

1. Describe how you have handled

2. Briefly describe

3. Briefly describe a situation where

4. Briefly describe what you like about 
Now that you have been introduced to the basics of probe questions, you will complete some exercises to apply the information you just learned. To begin, you will be presented with example interview responses. Also included is the interview question leading to each statement. Following that, the best strategies to use are identified. Your task is to write a probe question for each identified strategy using the list of probes on the previous page (basically, you are filling in the blanks from the probe list). Before beginning, please read through the example.

\section{EXAMPLE}

Question: Describe a time when you had to deal with a difficult coworker or customer on a job.

Statement: "When I was working as a salesclerk I hated working with this one guy in particular. Whenever I had to work with him I would do everything I could to stay away. I would try to find other tasks to work on so I could be alone or with other people."

Strategies:

Additional Information

Expansion

Probe Questions:

Tell me more about why you did not like working with this person.

I find your dislike for you coworker interesting. Could you tell me more about that?

Please look at the original probe questions (from the list) and note how each was adapted to fit the statement.

Please continue to the next page to begin the exercise. 


\section{Exercise 1}

Question: Describe a past situation requiring teamwork such that successful completion of your work was dependent on the work of your coworkers.

Statement: "I had a job working at an office where we had to coordinate schedules for the executives. I had to make sure I knew when other people had changed schedules so I could make changes where I needed."

Strategies:

Additional Information

Expansion

Probe Questions:

The next page contains the answers to these exercises. After you have written your questions, please compare your answers with the key. 


\section{Answer: Exercise 1}

The best probe strategies here are Additional Information and Expansion.

The statement is somewhat brief with little detail. Asking for additional information would be helpful. An additional information probe is "Tell me more about how coordinating schedules works."

Because the statement is so vague, it might be useful to ask a general question and allow the respondent to expand. An expansion probe would be "Could you give me some examples of this accurring?"

The description of events in the statement seems normal given the job description. Thus, the Inconsistency approach would not work well.

The interference strategy might be ineffective in this situation because the statement is vague rather than rich with detail.

You may have used a different probe and your wording may be different. However, the probe questions you generated should be similar to these in what they focus on. For example, in this exercise, it is difficult to form a probe regarding outcomes (e.g. Describe how things turned out regarding

When you have finished comparing your answers to the key please continue to the next page to continue with the remaining exercises. 


\title{
Lxercise 2
}

Question: Discuss a complex problem you have had to solve in the past.

Statement: "On my first job my main duty was to keep everything organized. After I had been working there a while I started completing other tasks. One day my boss asked me to figure out why the computer network was not working. Some of the computers were working and some were not. It was important to get them all working again because that is how they did business. It took me two days to figure out the problem."

Strategies:

\author{
Additional Information \\ Inconsistency
}

Probe Questions:

The next page contains the answers to these exercises. After you have written your questions, please compare your answers with the key. 


\section{Answer: Cxercise 2}

The best probe strategies here are Additional Information and Inconsistency.

The respondent does not indicate what the solution was, how it was obtained, or how it turned out. An additional information probe question would be "Tell me more about how you solved the problem."

The respondent indicates that they were asked to solve computer problems but that was not part of their job. An inconsistency probe question would be "Most of the time network problems are not normally handled by general employees. Why were you asked to solve it?

The Expansion strategy is plausible here but given the information in the statement it is better to ask more specific questions regarding the situation.

The interference strategy might be ineffective in this situation because the statement is in general terms rather than rich with detail.

You may have used a different probe and your wording may be different. However, the probe questions you generated should be similar to these in what they focus on.

When you have finished comparing your answers to the key please continue to the next page to continue with the remaining exercises. 


\section{Exercise 3}

Question: What are the differences between exploratory and confirmatory analyses?

Statement: "With exploratory analyses you do not have any prior expectations about the structure of the data. Instead of having a theory or an idea to drive your analysis, you let the data tell you the underlying structure. This approach is useful when there is no theory to explain relationships among your variables. One drawback is that you are capitalizing on chance and it is important to cross-validate the findings. When you want to test a theory you should use a confirmatory analysis. With this method you have an idea of how the data should look. If you run an exploratory analysis on these data, you will likely find a better fit but it is not likely that you can easily explain the pattern of results with theory. In general, confirmatory analyses are preferred over exploratory analyses."

Strategies:

Interference

Probe Questions:

The next page contains the answers to these exercises. After you have written your questions, please compare your answers with the key. 


\section{Answer: Exercise 3}

The best probe strategy here is Interference.

This statement is rich with details and asking an interference question might be effective. An interference probe would be "Briefly describe a situation where you lost control". This would then be followed by a probe question asking about the original response.

This statement is rich enough with details that asking for Additional Information or Expansion will not be useful.

Also, the statement seems normal, thus, it would be difficult to formulate an Inconsistency probe question here.

When you have finished comparing your answers to the key please continue to the next page to continue with the remaining exercises. 
Exercise

Question: Describe a time when you recently had to deal with a difficult coworker or customer on a past or current job.

Statement: "I was working as a waiter and we had a customer who would always try to get out of paying for some part of his bill. He would complain that the food was not prepared correctly or that the service was not good. When he was seated in my section I would take extra care to make sure he was satisfied, even though his complaints were mostly fake. I would make sure to write down everything he said about his order. If he wanted his stake medium-rare I would make sure and tell the cook to get it perfect. I also tried to push his order through faster than normal. I also made sure to check on his drink more frequently than usual and I asked him if everything was O.K. multiple times. The first time I served him that way was alright, he only complained about his meal. The second time I served him he didn't complain. I got server of the month for that."

Strategies:

None

Probe Questions:

The next page contains the answers to these exercises. After you have written your questions, please compare your answers with the key. 


\section{Answer: Exercise 4}

The statement here is complete. The respondent discusses the situation, what was done, reactions, and the outcome. Although it is easy to formulate an Additional Information or Expansion question, there is little to gain from asking a probe question.

When you have finished comparing your answers to the key please continue to the next page to continue with the remaining exercises. 


\section{Exercise 5}

Question: Describe a project that you had to complete with little or no direction.

Statement: "Last semester I had to complete a final project for a senior seminar. I had to do two things. First I had to review and critique an established theory in psychology. Then I had to conduct a complete research project to test that theory. It was a lot of work and it took me a long time to find a theory 1 wanted to test."

Strategies:

Inconsistency

Expansion

Probe Questions:

The next page contains the answers to these exercises. After you have written your questions, please compare your answers with the key. 


\section{Answer: Exercise 5}

Inconsistency and Expansion are strategies that will work well here.

The respondent indicates they were asked to conduct a complete research project in one semester, an unlikely task. An inconsistency probe would be "It is not normal for a single person to complete an entire research project in one semester. Why did it happen in your situation?

Because the statement is somewhat vague, it may be difficult to form a specific additional information question. However, it an expansion question would be "Please tell me more about the theory you tested.

The interference strategy might be ineffective in this situation because the statement is vague rather than rich with detail.

When you have finished comparing your answers to the key please continue to the next page to continue with the remaining exercises. 


\section{Txercise 6}

Question: Describe a past situation requiring teamwork such that successful completion of your work was dependent on the work of your coworkers.

Statement: "I was a research assistant for two years and was involved in several projects. Each one of them required coordination by all involved. The first project I worked on was the most complicated. I was given the job of gathering materials to use in the research. Before I could begin, my supervisor had to complete the lit review so I knew where to get the materials. Once that happened, I was able to finish. After that part was complete, we began to design the study, which involved all research members. Then I was the person in charge of collecting data. My supervisor had to wait until that was complete before she could write up the results."

Strategies;

Additional Information

Inconsistency

Expansion

Interference

Probe Questions:

The next page contains the answers to these exercises. After you have writen your questions, please compare your answers with the key. 


\section{Answer: Exercise 6 \\ Each of the strategies could easily work here.}

The respondent discusses duties performed for a project but never mentions the outcome. An additional information probe would be "Describe how things turned out regarding the project."

The respondent implies they were the only person doing data collection, a duty usually performed by multiple people. An inconsistency probe would be "In most situations similar to yours there are several people involved with data collection. Why was your situation different?"

The respondent is somewhat vague regarding specific actions performed. An expansion probe would be "You mentioned gathering materials but you did not describe it much. Would you please tell me more about gathering materials?"

Although the statement is vague in some respects, there is quite a bit of information there, thus, an interference probe might be useful. Such a probe might be "Briefly describe what you like about working with others."

Please compare your answers to the key and make sure you understand why each strategy is suited to the question or not.

You are now completed with training, inform the experimenter that you are ready to proceed to the interview phase. Your next task is going to be to interview someone using the techniques described in the training materials. You will be provided with the interview questions, the deception and truth criteria, and the list of probe questions available for you to ask during the interview.

After the interview, you will complete a questionnaire asking you to answer several questions. One of these will ask you to indicate a hiring decision as if you were interviewing this person for an actual job. Other questions will assess the honesty of the respondent as well as the usability of the checklist. 
Appendix $\mathbb{E}$

Interview Materials

\section{Interview Questions}

1. Describe a school or work project that you had to complete with little or no direction.

2. Describe a time when you recently had to deal with a difficult coworker or customer on a past or current job.

3. Discuss a complex problem you have had to solve in the past.

4. Describe a time when a project turned out to be more difficult than you thought it would be.

5. Tell me about a situation at school or work that required you to work and coordinate with two or more people in order to complete a task.

6. Describe a situation where you had to make a difficult decision that you knew would negatively affect someone.

7. Describe a situation that required you to complete multiple tasks simultaneously.

8. Please discuss a successful project that you completed as well as a project that did not turn out as you had hoped. 


\section{Criperia Checklist (Criteria type is in parentheses)}

During

Interview

$\square \square \square \square \square$ Boasting/Bragging(D)

Post

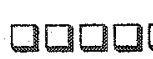

Discusses blockages to goal attainment (T)

Interview

वपD口D

प0口0 Discusses emotions of key participants (T)

ㅁㅁㅁ

प $\square \square \square$ Discusses goals or outcomes (T)

ㅁㅁㅁㅁㅁ

$\square \square \square \square \square$ Discusses lessons learned ( $\mathrm{T}$ )

ㅁㅁㅁㅁ

ㅁㅁㅁ

Dissatisfying or less than optimal outcome noted (T)

ㅁㅁㅁ

ㅁㅁㅁ

Does not discuss past behavior (D)

口व⿴囗口

ㅁㅁㅁㅁㅁ

Emphasizes own contributions to successful events (D)

ㅁㅁㅁㅁ

ㅁㅁ

Lack of emotion for emotional event (D)

ㅁㅁㅁ

घᄆ口ロロ

Lacks concrete descriptions (D)

ㅁㅁㅁ

๑๐口ロ

Mentions alternatives that were not used (T)

口व口व口

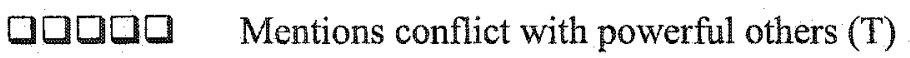

ロロロロロ

口ロ $\square \square$ Mentions unusual/distinct details (T)

口ロロロロ

पव口प No explanation of stereotypically "odd" behaviors (D)

ㅁㅁ

口QDO Reasons for evaluation of others NOT provided (D)

ㅁㅁㅁ

$\square \square \square \square \square$ Speaks in second person tense (D)

ㅁㅁㅁㅁ

ㅁㅁㅁ

\# Truth

\# Truth

\# Deception

\#Deception 


\section{Probe Questions}

\section{Additional Information}

1. Describe how things turned out regarding

2. Tell me more about (the situation, someone's reaction, etc.).

3. What were the circumstances surrounding (the situation)?

4. What did you do (regarding the situation)?

\section{Inconsistency}

1. Most of the time (some activity) is (difficult, not normal, performed by professionals, etc.) why were you (able to, asked to) complete it?

2. Typically (some event or reaction happens). Why did this not happen to you?

3. In most situations similar to yours your situation different? (some event or reaction occurs). Why was

4. It is not normal for (event or reaction to occur). Why did it happen in your situation?

\section{Expansion}

1. Please tell me more about

2. Could you give me some examples of ?

3. I find interesting. Could you tell me more information about that?

4. You mentioned but you did not describe it much. Would you please tell me more about (same as previous blank).

\section{Interference}

1. Describe how you have handled

2. Briefly describe

3. Briefly describe a situation where

4. Briefly describe what you like about 


\section{Appendix F \\ Treuth Script}

\section{Describe a school or work project that you had to complete with witle or no direction.}

In high school, I had to do a senior project to graduate. Even though there were guidelines, there was not much direction. I had to complete 20 hours of volunteer work, write up a description of the work, complete a research project and give a presentation on it, and then write a personal philosophy paper. It was difficult because each aspect of the project was so different from the others. The hardest part was finding volunteer work that I didn't mind doing. I ended up volunteering at a children's hospital which turned out pretty good. The whole project turned out alright and I graduated.

Criteria: Discusses blockages to goal attainment, discusses goals and outcomes

Describe a time when you recently had to deal with a difficult coworker or customer on a past or current job.

When I worked at Blockbuster we had a customer who always turned in movies late but would try to get out of paying for it. He would say he called ahead and was told that we would not charge him. Other times he would say the movie didn't work even though he had it for several days. He usually got very upset too. Whenever I talked to him, I would try to calmly explain our policies and tell him that he would have to pay. I also told him that if he should return non-working movies immediately or at least call. I also told him to make sure he talked to a manager about making sure he wasn't charged. He usually paid when I talked to him.

Criteria: Discusses emotions of key participants, discusses goals and outcomes

\section{Discuss a complex problem you have had to solve in the past.}

One time my mom left to help a friend. She was gone for 3 weeks and I had to help take care of my younger brother and sister. I also had to do all the cooking and laundry since my dad didn't do that. I am not a very good cook and I got into a bunch of arguments with my dad. I also messed up one of his shirts and he said I did it on purpose.

Criteria: Mentions conflict with powerful others, less than optimal outcome, lacks concrete descriptions

\section{Describe a time when a project anrned out to be more difficult than you thought it would be.}

One time I tried to install a stereo in my car. It was way more difficult than I thought. I had hooked up stereos in my house before but when I tried to hook it up I had no idea what wires were for what. After several hours I gave up and had a friend help me. He showed me what wires went where. I did some damage to the wires but we got it working. Next time I will just let someone else do it.

Criteria: Blockages to goal attainment, Discusses goals and outcomes, Discusses lessons learned 
Tell me about a situation at school or work that required you to work and coordinate with two or more people in order to complete at task.

I helped some professors with their research last year. Mostly I helped with collecting data but I also helped do some lit searches. Sometimes it would get hectic because I was working for two professors. One would ask me to get some articles and the other needed me to help with materials. That made things difficult because I needed to be in two places at once. I would have to try and coordinate between them because they didn't seem to communicate with each other very well. One time I got mad and started arguing with one of them about it. I shouldn't have done that but I was tired that day. I enjoyed working with them but if I am ever a research assistant again I will only work with one person in charge.

Criteria: Discusses lessons learned, Mentions conflict with powerful others, Discusses blockages to goal attainment

Describe a situation where you had to make a difficult decision that youknew would negatively affect someone.

One time my family was planning a vacation. Right before that I had agreed to help a friend who's grandmother had recently died. If I went with my family I would be letting my friend down but if $I$ stayed my mom would be really upset because we had never taken a vacation together. It was hard because I didn't want to upset anyone. I thought about asking another friend of mine to help but figured that would be tacky. So, I decided to spend the first few days with my friend, then I bought my own ticket to fly down and meet my parents. It was hard but I think I reached a happy medium.

Criteria: Discusses emotions of participants, Discusses goals and outcomes, mentions alternatives not used

Describe a situation that required you to complete multiple tasks simultaneously.

Anytime you have a job you have to complete tasks at the same time. It would probably be boring if you had a job where you only had to do one thing at a time. Secretaries have to do many things at once. My mom did that for a while and she was pretty good at it. I have never had a job where there was too much to do. At Blockbuster I had to answer the phone while helping a customer.

Criteria: Does not discuss past behavior, lacks concrete descriptions, speaks in second person tensePlease discuss a successful project that you completed as well as a project that did not turn out as you had hoped.

I was on prom committee in high school and we had to decide on themes for the prom. It wasn't very difficult, we all got along, got things done. As far as one that didn't work out, when I was on a welcoming committee it was a disaster. Nobody was very responsible for getting the things done that we had decided to do.

Criteria: Lacks concrete descriptions, Does not discuss past behaviors, Reasons for evaluations of others not provided, Less than optimal outcome 


\section{Appendix $\mathrm{G}$ \\ Deception Script}

\section{Describe a school or work project that you had to complete with little or no direction.}

In a marketing class we had to design a marketing strategy for a new product. That is all we were told. It was difficult to get started. I had to first decide what the new product was then I had to figure out how to market it. It was difficult but it worked out in the end because I am somewhat skilled at marketing.

Criteria: Boasting/Bragging, Discusses goals or outcomes

Describe a time when you recently had to deal with a difficult cowarker or customer on a past or current job.

When I worked at Applebee's we had a manager that was rude. I did not like him much and I think he did a really bad job. One time I got into an argument with him. It was really heated and I ended up quitting.

Criteria: Reasons for evaluation NOT provided, Lacks concrete descriptions, Does not discuss past behavior, Mentions conflict with powerful others

\section{Discuss a complex problem you have had to solve in the past.}

I was in an engineering class and we had a group assignment to figure out a way to create a bridge with little resources. It was complicated because we could only use materials in the surrounding environment. My group members were not very helpful. I came up with the plan and then when we were supposed to write it up I was the only one who did anything useful. No thanks to my group but the project turned out good because my plan was really creative.

Criteria: Boasting/Bragging, Discusses blockages to goal attainment, Emphasizes own contributions, Reasons for evaluation NOT provided

Describe a time when a project turned out to be more difficult than you thought it would be.

One time I tried to install a stereo in my car. It was way more difficult than I thought. I had hooked up stereos in my house before but when I tried to hook it up I had no idea what wires were for what. After several hours I gave up and had a friend help me. He showed me what wires went where. I did some damage to the wires but we got it working. Next time I will just let someone else do it.

Criteria: Blockages to goal attainment, Discusses goals and outcomes, Discusses lessons leamed 
Tell me about a situation at school or work that required you to work and coordinate with two or more people in order to complete a task.

When I worked with a group in political science class we had to work together to solve several diplomatic issues where each person on the team was responsible for getting specific things done.

Criteria: Lacks concrete descriptions, Does not discuss past behaviors

Describe a situation where you had to make a difficult decision that you knew would negatively affect someone.

It's hard when you have to make decisions that hurt other people. You have to be careful not to hurt them too much. You should also be careful that you think everything through really well. I avoid having to make decisions like that. One time I had to make a difficult choice about my family. I didn't want to do it so I just left for a few days and stayed at a hotel.

Criteria: Lacks concrete descriptions, Speaks in second person tense, No explanation of odd behavior

\section{Describe a situation that required you to complete multiple tasks simultaneously.}

Cooking requires multitasking. I like to cook but sometimes it gets complicated when you have a lot of stuff and only one oven. Last thanksgiving I had to cook a turkey and three other dishes. It was hard because they needed different temperatures and different times.

Criteria:Blockages to goal attainment, Lacks concrete descriptions

Please discuss a successful project that you completed as well as a project that did not turn out as you had hoped.

I was on prom committee in high school and we had to decide on themes for the prom. It wasn't very difficult, we all got along, got things done. As far as one that didn't work out, when I was on a welcoming committee it was a disaster. Nobody was very responsible for getting the things done that we had decided to do.

Criteria: Lacks concrete descriptions, Does not discuss past behaviors, Reasons for evaluations of others not provided, Less than optimal outcome 


\section{Appendix $\mathrm{H}$ \\ Post Interview Questionnaire 1}

1. In general, the interviewee was honest in relaying answers.

$\begin{array}{ccccccc}\begin{array}{c}\text { Strongly } \\ \text { disagree }\end{array} & \text { Disagree } & \begin{array}{c}\text { Somewhat } \\ \text { disagree }\end{array} & \begin{array}{c}\text { Neither } \\ \text { agree or } \\ \text { disagree }\end{array} & \begin{array}{c}\text { Somewhat } \\ \text { agree }\end{array} & \text { Agree } & \begin{array}{c}\text { Strongly } \\ \text { agree }\end{array} \\ 1 & 2 & 3 & 4 & 5 & 6 & 7\end{array}$

2. How deceptive was the interviewee?

$\begin{array}{ccccc}\text { Not at all } & \text { Slightly } & \text { Moderately } & & \text { Very } \\ \text { Deceptive } & \text { Deceptive } & \text { Deceptive } & \text { Deceptive } & \text { Deceptive } \\ 1 & 2 & 5 & 6 & 7\end{array}$

3. What is your hiring recommendation regarding the interviewee?

1. Do not hire

2. Hire

4. How quickly did you make your hiring decision?

$\begin{array}{ccccccc}\text { Very slowly } & \text { Somewhat } & & \text { Somewhat } & \text { Very } \\ 1 & \text { Slowly } & \text { slowly } & & \text { quickly } & \text { Quickly } & \text { quickly } \\ 1 & 2 & 3 & 4 & 5 & 6 & 7\end{array}$

5. How confident are you in your decision?

\begin{tabular}{|c|c|c|c|c|c|c|}
\hline $\begin{array}{c}\text { Very } \\
\text { unconfident } \\
1\end{array}$ & $\begin{array}{c}\text { Unconfident } \\
2\end{array}$ & $\begin{array}{c}\text { Somewhat } \\
\text { unconfident } \\
3\end{array}$ & 4 & $\begin{array}{c}\text { Somewhat } \\
\text { confident } \\
5\end{array}$ & $\begin{array}{c}\text { Confident } \\
6\end{array}$ & $\begin{array}{c}\text { Very } \\
\text { confident } \\
7\end{array}$ \\
\hline
\end{tabular}

6. How much did you like the interviewee?

$\begin{array}{ccccccc}\begin{array}{c}\text { Strongly } \\ \text { dislike }\end{array} & \text { Dislike } & \begin{array}{c}\text { Somewhat } \\ \text { dislike }\end{array} & \begin{array}{c}\text { Indifferent/ } \\ \text { Neutral }\end{array} & \begin{array}{c}\text { Somewhat } \\ \text { like }\end{array} & \text { Like } & \begin{array}{c}\text { Strongly } \\ \text { like }\end{array} \\ & 2 & 3 & 4 & 5 & 6 & 7\end{array}$

7. How difficult was the criteria checklist to use during the interview?

$\begin{array}{ccccccc}\text { Very } & \text { Somewhat } & \text { Somewhat } & \text { Very } \\ \text { easy } & \text { Easy } & \text { easy } & \text { difficult } & \text { Difficult } & \text { Difficult } \\ 1 & 2 & 3 & 4 & 5 & 6 & 7\end{array}$

Please review the interview on the T.V. when you are fimished with this questionnaire. 
Appendix I

Post Interview Questionnaire 2

8. In general, the interviewee was honest in relaying answers.

$\begin{array}{ccccccc}\text { Strongly } & \text { Somewhat } & \begin{array}{c}\text { Neither } \\ \text { agree or }\end{array} & \text { Somewhat } & & \text { Strongly } \\ \text { disagree } & \text { Disagree } & \begin{array}{c}\text { disagree } \\ \text { disagree }\end{array} & \text { agree } & \text { Agree } & \text { agree } \\ 1 & 2 & 3 & 4 & 5 & 6 & 7\end{array}$

9. How deceptive was the interviewee?

$\begin{array}{ccccc}\text { Not at all } & \text { Slightly } & \text { Moderately } & & \text { Very } \\ \text { Deceptive } & \text { Deceptive } & \text { Deceptive } & \text { Deceptive } & \text { Deceptive } \\ 1 & 2 & 5 & 6 & 7\end{array}$

10. How many additional criteria did you check while watching the interview?

$\begin{array}{lllllllll}0 & 1 & 2 & 3 & 4 & 5 & 6 & 7 & 8+\end{array}$

Please list any additional criteria you checked.

11. After viewing the video, what is your hiring recommendation regarding the interviewee? (It is acceptable to change you decision if you feel you want to)

1. Do not hire

2. Hire

12. Were there any criteria critical in making your decision? If yes, please list.

No Yes

13. Was there anything other than the criteria that helped you make your decision? If yes, please explain.

$$
\text { No Yes }
$$

If your decision is the same as before please stop here.

If your decision changed from before please answer the following questions.

14. If you changed your decision indicate why you did so.

15. If you changed your decision, where there any specific criteria leading to the change? If yes, please list.

No Yes 
Appendix J

Complete ANOVA Tables

\begin{tabular}{lllll}
\hline $\mathrm{DF}=2,122$ & $M S$ & $M S e$ & $F$ & $\eta$
\end{tabular}

Training (Structured Interview vs.

Deception Detection vs. Probe Questions)

Level of Honesty after Interview

Level of Deception after Interview

Quickness of Decision

Confidence in Decision

How much did you like interviewee

Difficulty of Checklist

Level of Honesty after Video

Level of Deception after Video

\# of Additional Criteria Checked

\# Truth Criteria During Interview

0.41

1.40

0.29

.07

4.16

0.79

$5.28 * *$

.28

0.64

1.50

0.42

.08

0.84

1.17

0.72

.11

2.24

0.99

2.27

7.51

1.82

4.13*

1.16

1.92

0.60

.10

2.94

0.73

$4.02 *$

.25

1.98

7.21

0.28

.06

\# Deception Criteria During Interview

160.13

28.81

$5.56 * * \quad .29$

\# Truth Criteria During Video

106.48

15.44

$6.89 * * \quad .32$

100.89

29.52

$3.42 *$

.23

\# Deception Criteria During Video

97.41

20.72

$4.70 * \quad .27$

\# Criteria Correct During Interview

\# Criteria Incorrect During Interview

136.12

16.66

$8.17^{* *}$

.34

64.12

19.14

$3.35^{*}$

.23

\# Criteria Correct During Video

46.04

14.69

$3.14^{*}$

.22

\# Criteria Incorrect During Video

121.23

22.94

$5.29 * *$

.28

711.47

163.55

$4.35^{*}$

.26

$\%$ Incorrect During Interview ${ }^{a}$

711.47

163.55

$\%$ Correct During Video ${ }^{\mathrm{a}}$

1292.15

154.29

$4.35^{*}$

.26

\% Incorrect During Video ${ }^{a}$

1292.15

154.29

$8.38^{* * *}$

$8.38^{* *}$

.35

.35

Note: $\eta=$ square root of partial effect size.

$* p<.05$

$* * p<.01$

${ }^{a}$ : indicates analysis conducted with percent $\mathrm{x} 100$ 


\begin{tabular}{|c|c|c|c|c|}
\hline $\mathrm{DF}=1,122$ & $M S$ & $M S e$ & $F$ & $\eta$ \\
\hline \multicolumn{5}{|l|}{ Interview Veracity (Truth vs. Deception) } \\
\hline Level of Honesty after Interview & 31.75 & 1.40 & $22.74 * *$ & .40 \\
\hline Level of Deception after Interview & 5.68 & 0.79 & $7.21 * *$ & .24 \\
\hline Quickness of Decision & 36.41 & 1.50 & $24.32 * *$ & .41 \\
\hline Confidence in Decision & 19.48 & 1.17 & $16.68 * *$ & .35 \\
\hline How much did you like interviewee & 8.68 & 0.99 & $8.77^{* *}$ & .26 \\
\hline Difficulty of Checklist & 2.78 & 1.82 & 1.53 & .11 \\
\hline Level of Honesty after Video & 38.64 & 1.92 & $20.09 * *$ & .38 \\
\hline Level of Deception after Video & 9.79 & 0.73 & $13.39 * *$ & .31 \\
\hline \# of Additional Criteria Checked & 54.04 & 7.21 & $7.49 * *$ & .24 \\
\hline \# Truth Criteria During Interview & 369.18 & 28.81 & $12.81 * *$ & .31 \\
\hline \# Deception Criteria During Interview & 676.65 & 15.44 & $43.81 * *$ & .51 \\
\hline \# Truth Criteria During Video & 378.70 & 29.52 & $12.83 * *$ & .31 \\
\hline \# Deception Criteria During Video & 852.43 & 20.72 & $41.15^{* *}$ & .50 \\
\hline \# Criteria Correct During Interview & 35.00 & 16.66 & 2.17 & .13 \\
\hline \# Criteria Incorrect During Interview & 0.78 & 19.14 & 0.04 & .00 \\
\hline \# Criteria Correct During Video & 13.23 & 16.66 & 0.79 & .08 \\
\hline \# Criteria Incorrect During Video & 3.69 & 22.94 & 0.16 & .03 \\
\hline$\%$ Correct During Interview ${ }^{\mathrm{a}}$ & 686.67 & 163.55 & $4.20 *$ & .18 \\
\hline$\%$ Incorrect During Interview $^{\mathrm{a}}$ & 686.67 & 163.55 & $4.20 *$ & .18 \\
\hline$\%$ Correct During Video ${ }^{a}$ & 196.34 & 154.29 & 1.27 & .10 \\
\hline$\%$ Incorrect During Video ${ }^{a}$ & 196.34 & 154.29 & 1.27 & .10 \\
\hline
\end{tabular}

Note: $\eta=$ square root of partial effect size.

$* p<.05$

$* * p<.01$

a: indicates analysis conducted with percent $x 100$ 


\begin{tabular}{|c|c|c|c|c|}
\hline $\mathrm{DF}=2,122$ & $M S$ & $\mathrm{MSe}$ & $F$ & $\eta$ \\
\hline \multicolumn{5}{|l|}{ Training $x$ Interview Veracity } \\
\hline Level of Honesty after Interview & 1.57 & 1.40 & 1.12 & 0.13 \\
\hline Level of Deception after Interview & 0.91 & 0.79 & 1.15 & 0.14 \\
\hline Quickness of Decision & 0.47 & 1.50 & 0.31 & 0.07 \\
\hline Confidence in Decision & 0.59 & 1.17 & 0.51 & 0.09 \\
\hline How much did you like interviewee & 0.94 & 0.99 & 0.95 & 0.12 \\
\hline Difficulty of Checklist & 0.16 & 1.82 & 0.09 & 0.03 \\
\hline Level of Honesty after Video & 0.47 & 1.92 & 0.25 & 0.06 \\
\hline Level of Deception after Video & 0.28 & 0.73 & 0.38 & 0.08 \\
\hline \# of Additional Criteria Checked & 3.10 & 7.21 & 0.43 & 0.08 \\
\hline \# Truth Criteria During Interview & 7.50 & 28.81 & 0.26 & 0.06 \\
\hline \# Deception Criteria During Interview & 5.48 & 15.44 & 0.36 & 0.08 \\
\hline \# Truth Criteria During Video & 48.24 & 29.52 & 1.63 & 0.16 \\
\hline \# Deception Criteria During Video & 4.97 & 20.72 & 0.24 & 0.06 \\
\hline \# Criteria Correct During Interview & 7.56 & 16.66 & 0.47 & 0.09 \\
\hline \# Criteria Incorrect During Interview & 10.59 & 19.14 & 0.55 & 0.09 \\
\hline \# Criteria Correct During Video & 6.54 & 14.69 & 0.45 & 0.08 \\
\hline \# Criteria Incorrect During Video & 31.53 & 22.94 & 1.37 & 0.15 \\
\hline$\%$ Correct During Interview $^{\mathrm{a}}$ & 448.21 & 163.55 & 2.74 & 0.21 \\
\hline$\%$ Incorrect During Interview & 448.21 & 163.55 & 2.74 & 0.21 \\
\hline$\%$ Correct During Video $^{\mathrm{a}}$ & 200.66 & 154.29 & 1.30 & 0.14 \\
\hline$\%$ Incorrect During Video ${ }^{a}$ & 200.66 & 154.29 & 1.30 & 0.14 \\
\hline
\end{tabular}

Note: $\eta=$ square root of partial effect size.

${ }^{a}$ : indicates analysis conducted with percent $\times 100$ 
Appendix $\mathrm{K}$

Tables of Descriptive Statistics

\begin{tabular}{|c|c|c|c|c|c|}
\hline Interview & & $\begin{array}{l}\text { Honesty } \\
\text { Following } \\
\text { Interview }\end{array}$ & $\begin{array}{l}\text { Deceptive } \\
\text { Following } \\
\text { Interview }\end{array}$ & $\begin{array}{c}\text { Honesty } \\
\text { Following } \\
\text { Video }\end{array}$ & $\begin{array}{c}\text { Deceptive } \\
\text { Following } \\
\text { Video }\end{array}$ \\
\hline \multirow[t]{4}{*}{ Truthful } & Training & & & & \\
\hline & $\begin{array}{l}\text { Structured } \\
\text { Interview }\end{array}$ & $5.80(1.28)$ & $1.83(1.04)$ & $5.59(1.47)$ & $1.86(0.80)$ \\
\hline & $\begin{array}{l}\text { Deception } \\
\text { Detection }\end{array}$ & $5.77(0.65)$ & $2.59(0.95)$ & $5.33(1.03)$ & $2.47(0.98)$ \\
\hline & $\begin{array}{l}\text { Probe } \\
\text { Questions }\end{array}$ & $5.98(0.97)$ & $1.86(0.77)$ & $5.67(1.20)$ & $1.96(0.95)$ \\
\hline \multirow[t]{4}{*}{ Deceptive } & Training & & & & \\
\hline & $\begin{array}{l}\text { Structured } \\
\text { Interview }\end{array}$ & $4.99(1.28)$ & $2.63(1.06)$ & $4.47(1.41)$ & $2.76(0.97)$ \\
\hline & $\begin{array}{l}\text { Deception } \\
\text { Detection }\end{array}$ & $4.75(1.32)$ & $2.76(0.81)$ & $4.12(1.71)$ & $2.98(0.83)$ \\
\hline & $\begin{array}{l}\text { Probe } \\
\text { Questions }\end{array}$ & $4.45(1.64)$ & $2.32(0.71)$ & $4.21(1.43)$ & $2.57(0.78)$ \\
\hline
\end{tabular}




\begin{tabular}{|c|c|c|c|c|c|c|}
\hline Interview & & $\begin{array}{c}\text { Quickness } \\
\text { of } \\
\text { Decision }\end{array}$ & $\begin{array}{c}\text { Confidence } \\
\text { in } \\
\text { Decision }\end{array}$ & $\begin{array}{c}\text { How much } \\
\text { liked } \\
\text { Interviewee }\end{array}$ & $\begin{array}{c}\text { Difficulty } \\
\text { of } \\
\text { Checklist }\end{array}$ & $\begin{array}{c}\text { Additional } \\
\text { Criteria } \\
\text { Checked }\end{array}$ \\
\hline \multirow[t]{5}{*}{ Truthful } & Training & & & & & \\
\hline & $\begin{array}{l}\text { Structured } \\
\text { Interview }\end{array}$ & $4.91(1.24)$ & $5.66(1.02)$ & $5.32(1.11)$ & $4.24(1.45)$ & $2.87(2.49)$ \\
\hline & Deception & & & & & \\
\hline & Detection & $5.02(1.35)$ & $5.59(0.94)$ & $5.47(0.94)$ & $4.54(1.08)$ & $2.93(2.71)$ \\
\hline & $\begin{array}{l}\text { Probe } \\
\text { Questions }\end{array}$ & $5.06(1.00)$ & $5.64(0.95)$ & $5.61(0.95)$ & $5.03(1.35)$ & $3.49(2.73)$ \\
\hline \multirow[t]{4}{*}{ Deceptive } & Training & & & & & \\
\hline & $\begin{array}{l}\text { Structured } \\
\text { Interview }\end{array}$ & $3.80(1.22)$ & $4.80(1.48)$ & $4.59(1.48)$ & $4.36(1.34)$ & $3.95(3.11)$ \\
\hline & $\begin{array}{l}\text { Deception } \\
\text { Detection }\end{array}$ & $4.15(1.47)$ & $4.63(1.31)$ & $5.29(1.31)$ & $4.94(1.44)$ & $4.64(3.01)$ \\
\hline & $\begin{array}{l}\text { Probe } \\
\text { Questions }\end{array}$ & $3.77(1.20)$ & $5.13(0.85)$ & $4.98(0.85)$ & $5.25(1.28)$ & $4.12(2.14)$ \\
\hline
\end{tabular}

Note: Means are adjusted for covariates. Number in parentheses indicates standard deviation. 


\begin{tabular}{cccccc}
\hline Interview & \multicolumn{1}{c}{$\begin{array}{c}\text { Truth } \\
\text { Criteria } \\
\text { Interview }\end{array}$} & $\begin{array}{c}\text { Deception } \\
\text { Criteria } \\
\text { Interview }\end{array}$ & $\begin{array}{c}\text { Truth } \\
\text { Criteria } \\
\text { Video }\end{array}$ & $\begin{array}{c}\text { Deception } \\
\text { Criteria } \\
\text { Video }\end{array}$ \\
\hline & \multicolumn{1}{c}{ Training } & & & & \\
& $\begin{array}{l}\text { Structured } \\
\text { Interview }\end{array}$ & $15.72(6.97)$ & $4.14(3.11)$ & $17.63(7.48)$ & $6.21(5.16)$ \\
& $\begin{array}{l}\text { Deception } \\
\text { Detection }\end{array}$ & $13.74(4.47)$ & $7.23(3.58)$ & $14.14(4.10)$ & $8.18(4.49)$ \\
& $\begin{array}{l}\text { Probe } \\
\text { Questions }\end{array}$ & $12.10(6.04)$ & $3.94(3.20)$ & $14.98(5.85)$ & $5.61(3.39)$
\end{tabular}

Deceptive

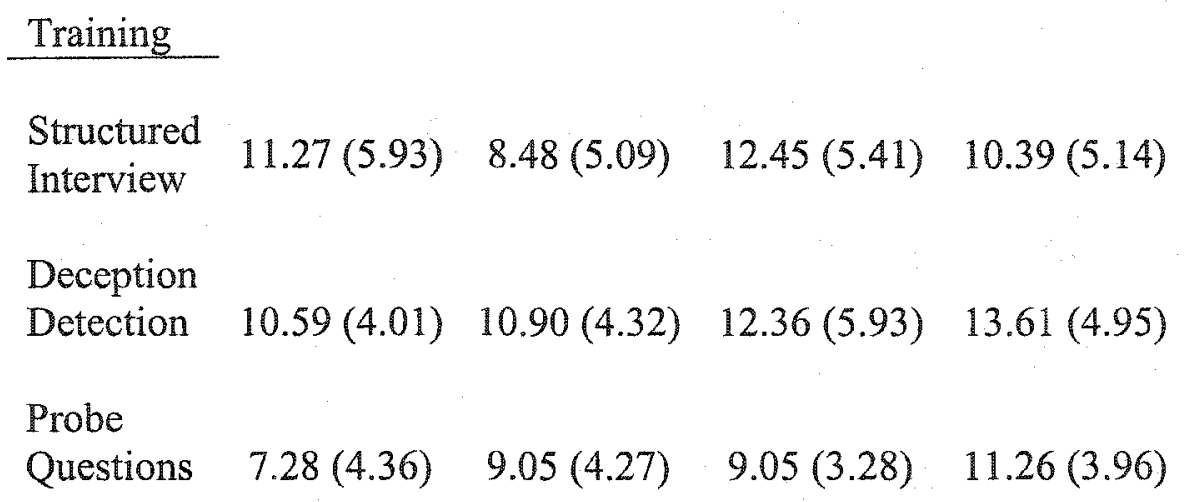

Note: Means are adjusted for covariates. Number in parentheses indicates standard deviation. 


\begin{tabular}{|c|c|c|c|c|c|}
\hline Interview & & $\begin{array}{c}\text { Criteria } \\
\text { Correct } \\
\text { Interview }\end{array}$ & $\begin{array}{l}\text { Criteria } \\
\text { Incorrect } \\
\text { Interview }\end{array}$ & $\begin{array}{l}\text { Criteria } \\
\text { Correct } \\
\text { Video }\end{array}$ & $\begin{array}{c}\text { Criteria } \\
\text { Incorrect } \\
\text { Video }\end{array}$ \\
\hline \multirow[t]{4}{*}{ Truthful } & Training & & & & \\
\hline & $\begin{array}{l}\text { Structured } \\
\text { Interview }\end{array}$ & $12.71(3.83)$ & $7.14(3.25)$ & $14.14(3.71)$ & $9.70(4.35)$ \\
\hline & $\begin{array}{l}\text { Deception } \\
\text { Detection }\end{array}$ & $14.75(4.08)$ & $6.21(3.66)$ & $15.14(4.07)$ & $7.19(4.44)$ \\
\hline & $\begin{array}{l}\text { Probe } \\
\text { Questions }\end{array}$ & $10.57(4.11)$ & $5.48(4.15)$ & $13.92(3.15)$ & $6.66(4.66)$ \\
\hline \multirow[t]{4}{*}{ Deceptive } & Training & & & & \\
\hline & $\begin{array}{l}\text { Structured } \\
\text { Interview }\end{array}$ & $12.61(4.77)$ & $7.14(5.75)$ & $14.12(4.36)$ & $8.72(5.55)$ \\
\hline & $\begin{array}{l}\text { Deception } \\
\text { Detection }\end{array}$ & $15.01(3.89)$ & $6.48(4.53)$ & $16.97(4.47)$ & $9.00(6.77)$ \\
\hline & $\begin{array}{l}\text { Probe } \\
\text { Questions }\end{array}$ & $12.31(4.02)$ & $4.03(4.93)$ & $15.15(4.39)$ & $5.16(2.92)$ \\
\hline
\end{tabular}

Note: Means are adjusted for covariates. Number in parentheses indicates standard deviation. 


\begin{tabular}{|c|c|c|c|c|c|}
\hline Interview & & $\begin{array}{l}\% \text { Correct } \\
\text { Interview }\end{array}$ & $\begin{array}{c}\% \text { Incorrect } \\
\text { Interview }\end{array}$ & $\begin{array}{c}\% \text { Correct } \\
\text { Video } \\
\end{array}$ & $\begin{array}{c}\% \text { Incorrect } \\
\text { Video }\end{array}$ \\
\hline \multirow[t]{4}{*}{ Truthful } & Training & & & & \\
\hline & $\begin{array}{l}\text { Structured } \\
\text { Interview }\end{array}$ & $.65(.10)$ & $.35(.10)$ & $.60(.12)$ & $.40(.12)$ \\
\hline & $\begin{array}{l}\text { Deception } \\
\text { Detection }\end{array}$ & $.72(.09)$ & $.28(.09)$ & $.71(.13)$ & $.29(.13)$ \\
\hline & $\begin{array}{l}\text { Probe } \\
\text { Questions }\end{array}$ & $.68(.17)$ & $.32(.17)$ & $.70(.16)$ & $.30(.16)$ \\
\hline \multirow[t]{4}{*}{ Deceptive } & Training & & & & \\
\hline & $\begin{array}{l}\text { Structured } \\
\text { Interview }\end{array}$ & $.67(.12)$ & $.33(.12)$ & $.64(.11)$ & $.36(.11)$ \\
\hline & $\begin{array}{l}\text { Deception } \\
\text { Detection }\end{array}$ & $.72(.13)$ & $.28(.13)$ & $.68(.13)$ & $.32(.13)$ \\
\hline & $\begin{array}{l}\text { Probe } \\
\text { Questions }\end{array}$ & $.80(.14)$ & $.20(.14)$ & $.76(.12)$ & $.24(.12)$ \\
\hline
\end{tabular}

Note: Means are adjusted for covariates. Number in parentheses indicates standard deviation. 